\title{
Epigenetics and stroke risk - beyond the static DNA code
}

This article was published in the following Dove Press journal:

Advances in Genomics and Genetics

15 October 2012

Number of times this article has been viewed

\author{
Charles C Matouk' \\ Paul J Turgeon ${ }^{2}$ \\ Philip A Marsden ${ }^{2,3}$ \\ 'Department of Neurosurgery, \\ Yale University School of Medicine, \\ New Haven, CT, USA; ${ }^{2}$ Department \\ of Laboratory Medicine and \\ Pathobiology, University of Toronto, \\ Toronto, Canada; ${ }^{3}$ Keenan Research \\ Centre and Li Ka Shing Knowledge \\ Institute, St Michael's Hospital, \\ Toronto, Canada
}

Correspondence: Philip A Marsden Li Ka Shing Knowledge Institute, St Michael's Hospital, 209 Victoria Street, Room 522, Toronto, Ontario M5B IC6, Canada

$\mathrm{Tel}+\mathrm{I} 4168471734$

Fax + I 4168645813

Email p.marsden@utoronto.ca
Abstract: Advances in high-throughput genome sequencing and genome-wide association studies indicate that only a fraction of estimated variability in stroke risk can be explained by genetic variation in protein-coding genes alone. Epigenetics is defined as chromatin-based mechanisms important in the regulation of gene expression that do not involve changes in the DNA sequence per se. Epigenetics represents an alternative explanation for how traditional risk factors confer increased stroke risk, provide a newer paradigm to explain heritability not explained by genetic variation, and provide insight into the link between how the environment of a cell can interact with the static DNA code. The nuclear-based mechanisms that contribute to epigenetic gene regulation can be separated into three distinct but highly interrelated processes: DNA methylation and hydroxymethylation; histone density and posttranslational modifications; and RNA-based mechanisms. Together, they offer a newer perspective on transcriptional control paradigms in blood vessels and provide a molecular basis for understanding how the environment impacts the genome to modify stroke susceptibility. This alternative view for transcriptional regulation allows a reassessment of the cis/trans model and even helps explain some of the limitations of current approaches to genetic-based screens. For instance, how does the environment exert chronic effects on gene expression in blood vessels after weeks or years? When a vascular cell divides, how is this information transmitted to daughter cells? This review provides an introduction to epigenetic concepts and a conceptual framework for understanding the shortcomings of an approach to stroke research that focuses solely on the static DNA code. Additionally, it will discuss classical and emerging mechanisms of epigenetic gene regulation that are especially relevant to large-vessel ischemic stroke.

Keywords: DNA methylation, endothelial nitric oxide synthase, histone posttranslational modifications, long noncoding RNA, ANRIL, heritability

\section{Introduction}

On average in the United States, someone has a stroke every 40 seconds and strokerelated deaths occur every 4 minutes. Stroke is ranked number four among all causes of death and is a leading cause of acquired disability in adults. ${ }^{1}$ With an estimated 7 million Americans over the age of 20 years having suffered a stroke, it represents a tremendous socioeconomic burden, with direct costs of $\$ 34.3$ billion in 2008. Despite intensive and sustained research efforts, it is estimated that between 2010 and 2030 the direct costs of stroke will escalate further by $238 \%$ as the prevalence of stroke increases by $25 \%$ over the same time period. ${ }^{2}$ It must be underscored that the problem of stroke is not confined to the US or other high-income countries, but is rather a global epidemic with broad socioeconomic relevance. ${ }^{3}$ For example, more than $85 \%$ 
of all strokes worldwide occur in low- and middle-income countries. ${ }^{4,5}$ Stroke ranks as the second-leading cause of mortality worldwide in adults over the age of 15 years. It represents the fifth-leading cause of disability-adjusted life years lost, just after HIV/AIDS. ${ }^{4-6}$ The problem is worsening due to an aging population and changes in the distribution of modifiable cardiovascular risk factors in developing and third-world countries. ${ }^{4,7}$ Newer approaches for understanding stroke pathogenesis are urgently needed.

Stroke is defined as a clinical syndrome characterized by an acute loss of neurological function, with symptoms lasting greater than 24 hours, that results from a vascular problem. ${ }^{8}$ Implicit in this definition of "clinical syndrome" is the idea that stroke is not a single disease. This definition encompasses both ischemic and hemorrhagic stroke, although the former accounts for nearly $90 \%$ of the overall stroke burden. ${ }^{1}$ Ischemic stroke does not represent a homogeneous group: large-vessel atherosclerosis, cardioembolism, and smallvessel occlusion are important pathomechanistic subtypes. ${ }^{9}$

Of the common forms of ischemic stroke, perhaps the greatest strides have been made in understanding largevessel atherosclerosis, due to its prevalence and commonality with atherosclerotic disease of the coronary and peripheral vasculatures. In this stroke subtype, traditional risk factors that increase the risk of stroke are well known, such as hypertension, dyslipidemia, and smoking. But the molecular mechanisms that impart an increased risk to the individual are poorly understood. Undoubtedly, genetic predisposition is an important contributory factor for defining an individual's stroke risk. Evidence from twin and other studies of familial aggregation of stroke provides estimates of heritability. ${ }^{10}$ However, recent genome-wide association studies (GWASs) suggest that only a fraction of the estimated heritability can be explained by genetic variation alone. Perhaps the genetic contribution to stroke risk is overestimated, since uninterrogated genetic elements may contribute to heritable risk. ${ }^{11} \mathrm{We}$ argue that the impact of gene-environment interactions has been underestimated and can be more fully addressed by an epigenetic theory of complex, non-Mendelian disease. ${ }^{12-14}$

Epigenetics is broadly defined as chromatin-based mechanisms of gene expression that do not involve changes to the DNA sequence per se. ${ }^{13}$ Prominent examples include DNA methylation, the density of histones and their posttranslational modifications, and RNA-based pathways (Figure 1). These molecular mechanisms are the "nuts and bolts" on which three founding principles of epigenetic theory are grounded. First, the same DNA sequence can demonstrate variable expressivity depending on its chromatin state. This chromatin state can be inherited in mitosis. Second, epigenetic modifications are more malleable than the static genetic code, and therefore potentially more responsive to environmental stimuli, both intrinsic and extrinsic to the cell, as well as short-term therapeutic intervention. Third, the possibility of meiotic inheritance of epigenetic modifications allows for the transference of disease susceptibility from parent to child outside the context of the classical genetic code. ${ }^{12,13}$ Taken together, epigenetic theory may help to explain how traditional risk factors confer increased stroke risk, and account for the heritability that is not explained by known genetic variation.

The aims of this review are to provide an introduction to epigenetic concepts applicable to future stroke research and to discuss classical and emerging mechanisms of epigenetic gene regulation, especially those that are relevant to largevessel ischemic stroke.

\section{Ischemic stroke risk: why the static code is not enough}

The evidence for a genetic liability in ischemic stroke is very strong. Perhaps the most definitive evidence comes from animal studies. ${ }^{15}$ For example, in the well-established mouse model of focal cerebral ischemia involving permanent occlusion of the distal middle cerebral artery, final infarct volume is highly dependent on the inbred mouse strain. ${ }^{16-19}$ In one recent study, there was as much as a 30 -fold difference in infarct volume between inbred mouse strains at the phenotypic extremes. Heritability of the trait of infarct volume was 0.88 , arguing for a powerful genetic contribution. ${ }^{19}$ However, it is important to remember that such studies rigorously control the environment of the animal. It is reasonable to infer that gene-environment interaction will be much more relevant in the human setting. ${ }^{19}$

In human ischemic stroke, several well-studied monogenic disorders increase stroke risk and account for some familial aggregation of ischemic stroke. Prominent examples include cerebral autosomal dominant arteriopathy with subcortical infarcts and leukoencephalopathy (CADASIL) due to NOTCH3 mutations, Fabry disease due to GLA mutations, and sickle-cell disease due to $H B B$ mutations. ${ }^{10,20}$ These stroke syndromes are rare, and responsible for only a fraction of the overall stroke burden. In the general population, however, demonstrating a genetic predisposition to stroke risk has been more challenging. Nonetheless, accruing evidence from larger and better-designed studies argues for a significant heritable contribution. For example, a recent analysis of the prospectively collected Framingham Heart Study demonstrated a threefold increased risk of offspring stroke with documented parental stroke by 65 years of age. ${ }^{21}$ These results parallel those from earlier twin, case-control, and cohort studies pointing to a genetic contribution to ischemic 


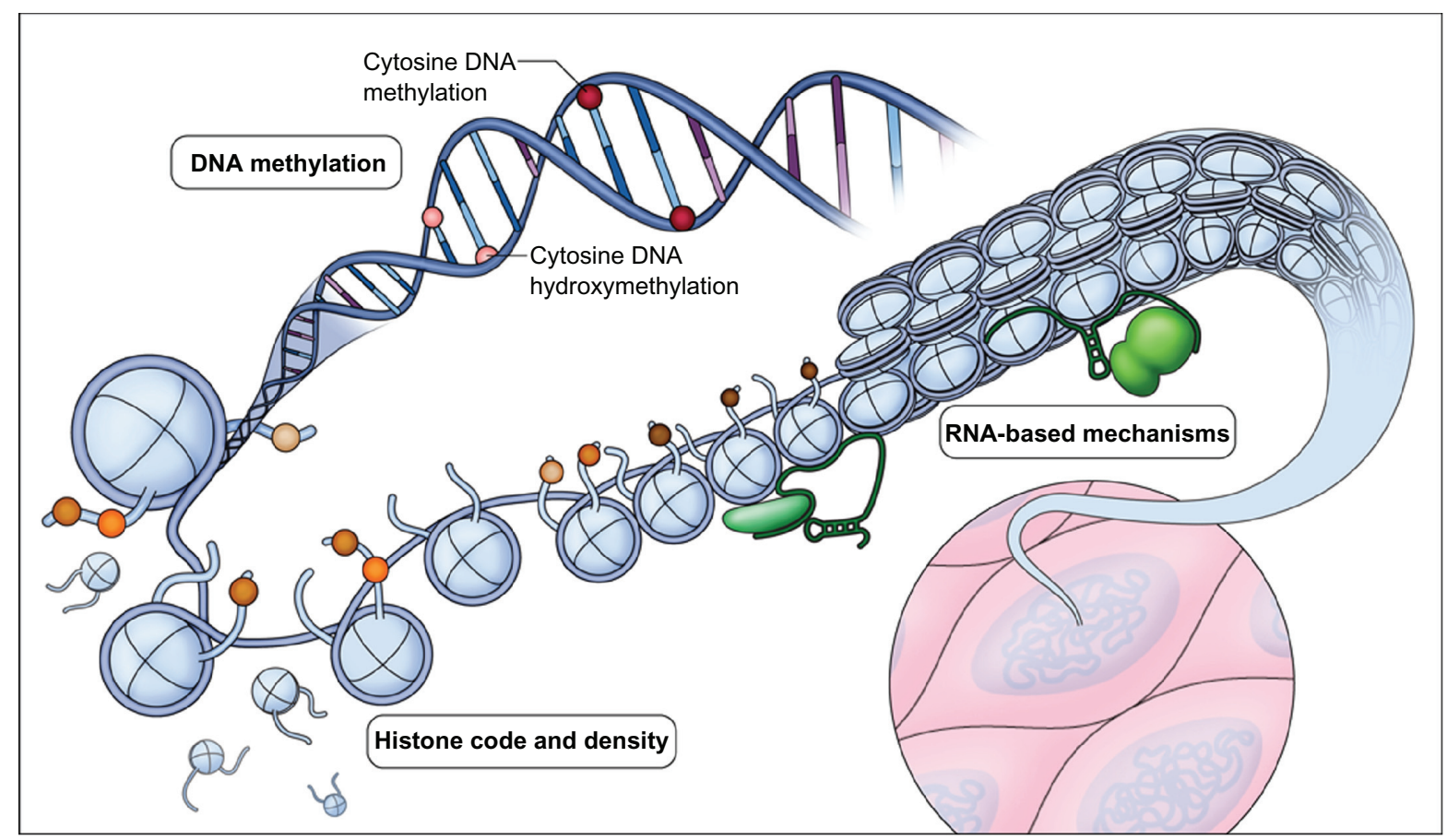

Figure I Epigenetics can be separated into three distinct but highly interrelated processes: DNA methylation; histone density and posttranslational modifications; and RNAbased mechanisms.

Notes: DNA methylation is a repressive mark and occurs symmetrically almost exclusively in the context of CpG dinucleotides in mammals. It refers to the addition of a methyl group to the 5-position of cytosine and is classified as the "fifth base of DNA". Recently described 5-hydroxymethylation also occurs at CpG dinucleotides and has been described as the "sixth base of DNA", and may serve as an intermediate for active demethylation. Histone density and posttranslational modifications refers to the presence of histones and $\mathrm{N}$-terminal histone tail posttranslational modifications that modulate histone protein-DNA interactions. This can alter the accessibility of chromatin remodeling complexes and transcription factors to the chromatin and alter gene transcription. RNA-based mechanisms including long noncoding RNAs interact with chromatin and chromatin-modifying complexes in cis or trans to modulate gene expression.

stroke risk. ${ }^{10,20}$ Studies of intermediate phenotypes, such as carotid-artery intima-media thickness, also demonstrate significant heritability ranging from 0.55 to $0.71 .{ }^{22-25}$ Finally, recent GWASs of many thousands of patients have identified genetic susceptibility loci for ischemic stroke: most prominently and consistently the chromosome 9p21 (chr9p21) locus. ${ }^{26-28}$ In a recent meta-analysis of eight ischemic stroke studies, the chr9p21 locus was shown to be a risk factor for large-vessel ischemic stroke with a modest effect size (odds ratio [OR], 1.20 [95\% CI, 1.08-1.33, $P=0.0006]$ ). ${ }^{26}$ Importantly, this increased risk was independent of traditional cardiovascular risk factors, suggesting that it may exert its influence via novel mechanistic pathways. We will discuss this locus in more detail below. More recently, a large GWAS study reported for 1162 large vessel ischemic stroke cases. When compared with 1244 control patients a new susceptibility locus on chromosome $6 \mathrm{p} 21.1$ was identified $\left(\mathrm{OR}=1.62\left[95 \%\right.\right.$ CI 1.36 to $\left.\left.1.93, P=3.9 \times 10^{-8}\right]\right)$. Importantly, this was replicated in multiple independent population cohorts. ${ }^{29}$ Interestingly, this SNP falls within a region of the genome that does not contain known protein coding genes.

Epigenetic mechanisms may also play a role in the regulation of gene expression after ischemic insult in adults.
There is small but accumulating evidence to suggest that DNA methylation and chromatin changes occur in cells following ischemia. $^{30,31}$ For example, classical trans/cis regulators of neuronal gene expression seem to interface with epigenetic pathways, especially in disease. A major mechanism relevant to neuronal-enriched gene expression is the neuron-restricted silencing factor/repressor element-1 silencing transcription factor (REST). REST was originally described as a repressor of neuronal gene expression in nonexpressing cell types. REST is a transfactor that binds to the RE-1 cis DNA element. REST/RE-1 trans/cis interactions are key to establishing and maintaining neuronal gene-expression pathways, and hence phenotype. ${ }^{30,32,33}$ In mature neurons, REST is quiescent but can be activated by ischemia. ${ }^{34}$ Recent findings have shown that epigenetic remodeling of chromatin occurs in ischemiainduced neuronal cell death and can be abrogated with knockdown of the REST trans complex. ${ }^{30}$ Therefore, epigenetic pathways interface with REST and thus is relevant in disease. The use of these epigenetic mediators in therapeutics should be approached with caution. As much as there are theoretical applications to the modulation of epigenetic regulators, as with the use of microRNAs in therapeutics, they must be fully understood for safe and effective use in therapy. ${ }^{32,35-37}$ 
Currently, epigenetic modulators as indicators of prognosis have shown some promise. ${ }^{35,38}$

Taken together, a genetic contribution to human ischemic stroke susceptibility is certain, but less so is the magnitude of that contribution. The remainder of this section will highlight three observations regarding ischemic stroke syndromes that appear to be poorly explained by traditional models. An epigenetic theory of complex, non-Mendelian disease may offer newer insights.

\section{Discordance of monozygotic twins for ischemic stroke}

Classical twin studies are a powerful research tool to assess the genetic contribution to human disease. ${ }^{39,40}$ By comparing the prevalence of a disease phenotype among monozygotic (MZ) versus dizygotic (DZ) twins, the relative genetic contribution can be estimated, and is referred to as heritability. This strategy is based on the principle that MZ twins are (nearly) genetically identical, while DZ twins share $50 \%$ of segregating DNA sequence variation. In theory, an increased prevalence of disease amongst $\mathrm{MZ}$ versus $\mathrm{DZ}$ twins points to a genetic contribution to disease phenotype. For example, in a population-based study of Danish twins, the heritability estimate for the liability to stroke death was 0.32 , suggesting a strong genetic predisposition..$^{41}$ This calculation was based in part on concordance rates for stroke death of $10 \%$ and $5 \%$ for MZ and DZ twins, respectively. Similarly, in a separate study of male twin pairs born between 1917 and 1927 who were US veterans, proband concordance rates were $17.7 \%$ and $3.6 \%$ for MZ and DZ twins, respectively, again suggesting a strong genetic component of stroke risk. ${ }^{42}$ Closer inspection of these data, however, reveals a paradox. Although stroke is more prevalent amongst $\mathrm{MZ}$ versus $\mathrm{DZ}$ twins, the concordance for stroke within MZ twin pairs is poor. What explains the discordance for stroke within MZ twin pairs? The familiar argument proposes that environmental exposures, both intrinsic and extrinsic to the cell, eg, cigarette smoking, poor diet, and a sedentary lifestyle, differentially affect the members of a twin pair, thereby altering their individual stroke risk. But how these differential exposures impact the genome to impart enhanced disease susceptibility remains poorly understood. ${ }^{12,13}$

\section{Phenotypic variability in CADASIL and other monogenic stroke syndromes}

CADASIL is an autosomal dominant disease and the most common cause of inherited stroke in adults. ${ }^{10,20}$ It is characterized by five main symptoms - migraine with aura, subcortical strokes, mood disorder, apathy, and cognitive dysfunction - and initially becomes manifest in young and middle-aged adults. ${ }^{43}$ CADASIL is a severe disease that progresses to dementia, mutism, and a bedridden state over the course of approximately 25 years. Characteristic magnetic resonance imaging (MRI) findings typically precede clinical symptoms by several years. Eventually, they include confluent white matter changes in periventricular areas and the centrum semiovale. CADASIL is a systemic arteriopathy of small and medium-sized vessels caused by mutations in a single gene, $\mathrm{NOTCH} 3$, a transmembrane receptor predominantly expressed in vascular smooth muscle cells (VSMCs). Despite tremendous advances in the pathophysiology and molecular genetics of CADASIL, and the recent description of murine transgenic models, a specific treatment is not yet available. ${ }^{43,44}$ Complicating treatment and prognostication of patients with CADASIL is the well-recognized extreme variability in clinical phenotype of patients of the same age, patients within the same family, and even patients carrying the same causative NOTCH3 mutation. ${ }^{45-49}$ For example, Mykkanen et al reported that 18 of 21 Finnish CADASIL pedigrees shared a common ancestral mutation - a C457T missense mutation in exon 3 resulting in an $\mathrm{R} 133 \mathrm{C}$ substitution. ${ }^{49}$ The age at first-ever stroke among these family members varied from 28 to 71 years. ${ }^{48,49}$ Opherk et al studied 151 CADASIL patients from 95 families to better understand the heritability of MRI lesion volume. ${ }^{46}$ Consistent with previous reports, no differential effect of NOTCH3 genotypes on lesion volumes was observed; however, heritability estimates were high, ranging from 0.634 to 0.738 , depending on adjustments for identified covariates. From a genetics perspective, these data argue for the strong contribution of modifier genes to MRI lesion volume, ie, a quantitative marker for disease severity, in CADASIL. However, such modifier genes have yet to be identified. Epigenetic theory offers a different perspective. Consider the recent report of different clinical phenotypes in MZ CADASIL twins with a causative NOTCH3 mutation. ${ }^{48}$ In this example, modifier genes are not likely to be contributory, and so alternative explanations are required. Herein, we have used CADASIL as a specific example; however, other monogenic stroke syndromes, ie, Fabry disease and sickle-cell disease, demonstrate similar phenotypic variability poorly explained by current disease models. ${ }^{10,20}$

\section{Genome-wide association studies of large- vessel ischemic stroke: missing heritability and epigenetic determinants of stroke risk}

GWAS is a powerful technique to discover associations between variation in the genome and phenotypic variance 
in a patient cohort. Pragmatically, this approach involves evaluating several hundred thousand to more than a million single-nucleotide polymorphisms (SNPs) in thousands of individuals using commercial "SNP chips" that capture most but not all common variation in the genome. The comparison group, or cohort population, needs to be carefully controlled for confounding variables. Especially important is the degree of genetic admixture and background. The power of the technique is threefold: (1) it is unbiased, not assuming any biological knowledge about a clinical phenotype; (2) it takes advantage of haplotype blocks, which limits the number of SNPs that need to be tested; and (3) it is statistically powerful in its ascertainment of common genomic variation. Replication in independent patient and control cohorts is key. For these reasons, GWASs represent a major advance compared to traditional candidate gene and familial linkage studies for exploring the genetic landscape of complex, non-Mendelian diseases. Indeed, the method has been successfully applied to such myriad conditions as Crohn's disease, systemic lupus erythematosus, early onset myocardial infarction, and many others, including ischemic stroke. ${ }^{50,51}$

However, a discrepancy has emerged in these reams of data. Conceptually, the ability of GWASs to identify genetic susceptibility loci is reliant on the "common disease, common variant" hypothesis, which posits that common diseases are attributable to common genomic variations present in at least $1 \%-5 \%$ of the population. ${ }^{51}$ The discrepancy in GWASs as applied to a vast majority of common human diseases, or complex traits, is that the identified common variant(s) confer incremental risk (1.1-1.5-fold) and explain only a small fraction of the estimated heritability. Perhaps the best example is human height, a classic complex trait, with an estimated heritability of $80 \%$. GWASs have identified more than 50 susceptibility loci that together explain only $5 \%$ of phenotypic variance. ${ }^{51-53}$ Large-vessel ischemic stroke and its intermediate phenotypes are no exception. ${ }^{11}$ What accounts for this "missing heritability" in GWASs of complex diseases? Several explanations have been suggested. Some argue that as-of-yet uninterrogated common genomic variants of even smaller effect sizes will additively account for the missing heritability. Others argue that difficult-to-study gene-gene interactions will compound effect sizes. Still others suggest that rare variants with possibly larger effect sizes, poorly detected using currently available SNP chips, are the missing pieces in the heritability puzzle. However, empirical data for these hypotheses are lacking at this time in ischemic stroke. ${ }^{51,54}$ We argue, as others have, that epigenetic theory provides an alternative conceptual framework to account for, at least in part, the missing heritability of complex diseases. ${ }^{55}$ It is tantalizing, therefore, that a method designed to identify genomic susceptibility loci has instead identified epigenetic effectors as the major determinants of large-vessel ischemic stroke liability. For example, the chr9p21 locus is the most replicated marker of coronary artery disease, myocardial infarction, and large-vessel ischemic stroke. ${ }^{26-28}$ Intriguingly, this genomic region is devoid of protein-coding genes, but instead contains a long noncoding RNA (lncRNA) - antisense noncoding RNA in the INK4 locus $(A N R I L)$ - a mediator of epigenetic gene regulation. ${ }^{56}$ Most recently, the largest GWAS of ischemic stroke to date identified a new association with the HDAC9 gene in large-vessel ischemic stroke with a relatively large estimated effect size $(\mathrm{OR}=1.38$ [95\% CI, $\left.\left.1.22-1.57, P=1.87 \times 10^{-11}\right]\right) .{ }^{28} H D A C 9$ is a member of the histone deacetylases, classical epigenetic regulators of gene expression. Further examination of this finding is needed, as the authors suggest distinct genetic architectures for different stroke subtypes, implying a function for $H D A C 9$ in distinct epigenetic events. Finally, a more limited study uncovered an association between carotid-artery intima-media thickness and $H D A C 4 .{ }^{57}$ The pattern is clear: unbiased views of genetic variation in large-vessel ischemic stroke liability point to a prominent role for epigenetics.

Taken together, these three observations - discordance of MZ twins for stroke, phenotypic variability in monogenic stroke syndromes, and the missing heritability in GWASs - provide examples of stroke susceptibility (including heritability) that are poorly explained by traditional disease models. The next section will introduce the "nuts and bolts" of epigenetic gene regulation and articulate an epigenetic theory of complex non-Mendelian disease.

\section{Molecular nuts and bolts: epigenetic effectors of gene expression and theory of complex disease}

The compaction required of genomic DNA to fit into a eukaryotic cell nucleus is staggering. The haploid human genome is made up of approximately 3.3 billion DNA base pairs. ${ }^{58}$ If we estimate that an average human adult is comprised of $10^{13}$ cells, the total length of DNA in a single individual would span $2 \times 10^{13}$ meters, or roughly the distance from the earth to the sun and back 70 times. ${ }^{59}$ This phenomenal degree of compaction is achieved by the packaging of DNA into a DNA-protein complex referred to as chromatin. Chromatin structure is based on a fundamental repeating unit conserved across all eukaryotic genomes - the nucleosome. A human nucleosome comprises 146 bp of DNA 
wrapped around an octamer of core histone proteins; namely, two molecules each of H2A, H2B, H3, and H4. Adjacent nucleosomes are linked by shorter, species-specific stretches of DNA associated with a fifth histone protein - histone H1 ${ }^{60}$ The molecular pathways that regulate the structure and accessibility of chromatin without changing the $A-C-G$ - $T$ genetic code constitute the "nuts and bolts," or effectors, of epigenetic theory. They are discussed separately below, but constitute a highly integrated and evolutionarily conserved system for regulated gene expression (Figure 1). ${ }^{12-14}$

\section{DNA methylation: adding fifth}

\section{and sixth bases to the genetic code}

DNA methylation refers to the covalent modification of the 5 -position of cytosine to create 5 -methylcytosine $(5 \mathrm{mC})$, the "fifth base of DNA."61 This apparently simple modification adds a significant layer of epigenetic complexity to regulated gene expression. DNA methylation is generally viewed as a repressive mark associated with the inhibition of transcriptional initiation. For example, it is strongly implicated in the silencing of repetitive (parasitic) DNA sequences, $\mathrm{X}$-chromosome inactivation, genomic imprinting, mammalian embryogenesis, and cellular differentiation. ${ }^{13,61,62}$

The molecular mechanisms underlying DNA methylation and their influence on gene expression are increasingly well understood. This unique pyrimidine $(5 \mathrm{mC})$ continues to base-pair with guanine, and in mammals is restricted (almost exclusively) to $\mathrm{CpG}$ dinucleotides. ${ }^{13,61}$ A curiosity in the evolution of the mammalian genome is that it is CpG-depleted. However, certain regions of the genome are relatively spared from this depletion and are referred to as CpG islands. ${ }^{63,64}$ They are associated with the $5^{\prime}$-regulatory regions (or promoters) of $\sim 60 \%-70 \%$ of human genes and intergenic, repetitive DNA sequences such as Alu elements. ${ }^{65}$
Interestingly, $\mathrm{CpG}$ dinucleotides in repetitive DNA sequences are densely methylated (and transcriptionally silent), whereas those associated with gene promoters are typically unmethylated. ${ }^{13,61,62}$

In mammals, the addition of a methyl group to the 5-position of cytosine is catalyzed by three distinct DNA methyltransferases (DNMTs) encoded by distinct genes, each on different chromosomes: DNMT1, DNMT3a, and DNMT3b (Figure 2). The latter two enzymes are responsible for de novo methylation and the establishment of DNA methylation patterns during embryogenesis and early development. ${ }^{66}$ In contradistinction, DNMT1 attends to maintenance methylation and the propagation of DNA methylation patterns during mitotic cell division from parent to daughter cells (Figure 2). To accomplish this task, it preferentially binds to hemimethylated DNA and is localized to the replication fork. In this way, methylation on the nascent DNA strand is informed by the methylation pattern of the complementary strand. ${ }^{61,66}$

DNA methylation patterns are transmitted to daughter cells in a semiconservative fashion. The error rate for DNA methylation conservation is significantly greater than the error rate for transmission of the $A-C-G-T$ static DNA code. Notwithstanding this increased error rate, DNA methylation is a remarkably stable epigenetic modification. However, DNA demethylation does occur and is best characterized in specific developmental windows, eg, in preimplantation embryos and primordial germ cells. This has generally been thought to occur via a passive (replication-dependent) process mediated by a regulated absence or reduction of DNMT activity. ${ }^{66}$ Examples of rapid and active (replicationindependent) DNA demethylation events in response to cell signaling and cellular differentiation are accruing, but a plausible mechanism has been elusive. ${ }^{67-70}$ Most recently, great

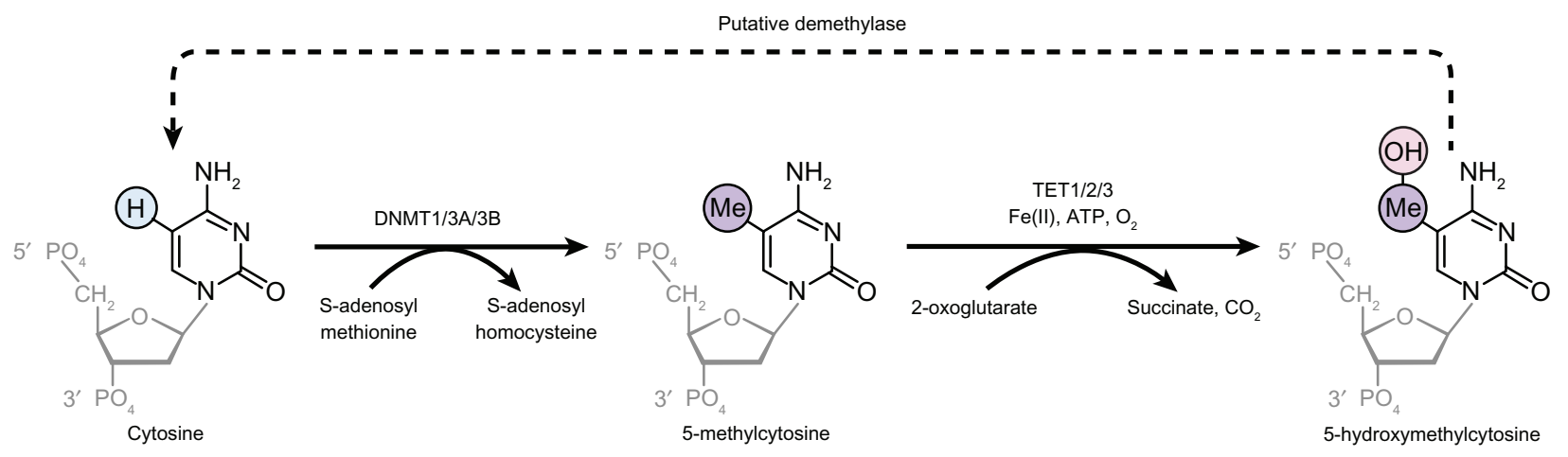

Figure 2 The addition of a methyl group at the 5-position of cytosine is mediated by the DNA methyltransferase (DNMT) family, where S-adenosylmethionine serves as the methyl donor.

Notes: The ten-eleven translocation (TET) family of enzymes is able to oxidize 5-methylcytosine to 5-hydroxymethylcytosine in an oxygen-dependent reaction requiring adenosine triphosphate and 2-oxoglutarate. Cytosine can then be generated from the action of putative demethylases on 5-hydroxymethylcytosine, but has not yet been fully described. 
excitement in the field has been generated over the rediscovery of $5 \mathrm{hmC}$ as an intermediate in an active demethylation pathway. ${ }^{71,72}$ The formation of $5 \mathrm{hmC}$ is an oxidative reaction from $5 \mathrm{mC}$ that is catalyzed by the ten-eleven translocation (TET) family in mammals. The TET1, TET2, and TET3 proteins appear to play a role in diverse biological processes from pluripotent stem-cell differentiation to development of leukemia. ${ }^{73}$ The TET enzymes are capable of catalyzing $5 \mathrm{mC}$ to $5 \mathrm{hmC}, 5$-formylcytosine, and 5-carboxylcytosine through successive oxidation reactions. ${ }^{74}$ The enzymatic players responsible for active DNA demethylation are still not well understood, and may also include the AID/APOBEC (activation-induced cytidine deaminase/apolipoprotein B mRNA-editing catalytic polypeptides) family, a family of base excision repair glycosylases, in addition to the TET family discussed above. ${ }^{75}$ At a pragmatic level, the two classical techniques for the assessment of DNA methylation are bisulfite sequencing and methylation-sensitive restriction enzyme digests, neither of which is capable of distinguishing between $5 \mathrm{mC}$ and $5 \mathrm{hmC} .{ }^{75}$ These fundamental discoveries poise the field for a rethinking of DNA methylation dynamics in regulated gene expression, and the establishment and maintenance of cellular identity.

How does DNA methylation regulate gene expression? Two putative mechanisms are best characterized. First, a methyl group added to the 5-position of cytosine alters the structure of DNA by projecting into the major groove of the DNA double helix, thereby potentially impacting sequencespecific recruitment of DNA-binding proteins, including transcriptional regulators. ${ }^{13,61}$ Prominent examples include Myc, activator protein-2, hypoxia-inducible factor- $1 \alpha$, and the insulator protein CTCF. ${ }^{13,61}$ The relative contribution of DNA methylation in defining trans factor binding is poorly understood. The second mechanism attests to the highly integrated nature of epigenetic pathways and is reliant on a family of methyl-CpG binding domain (MBD) proteins. These include MBD1, MBD2, MBD4, MeCP2, and Kaiso. These proteins can block the binding of activating trans factors and recruit to the chromatin histone-modifying enzymes, chromatin remodelers, and even RNA molecules that cooperatively act to silence gene expression. ${ }^{13,61,76}$ Intriguingly, mammalian MBD3 does not bind to methylated DNA, but is an integral member of the nucleosome remodeling and deacetylase complex and is associated with repressive chromatin structure. ${ }^{77,78}$ The recent demonstration that it specifically recognizes and binds to $5 \mathrm{hmC}$ but not $5 \mathrm{mC}$ supports the emergence of $5 \mathrm{hmC}$ as the putative "sixth base of DNA."79

\section{Histone proteins and posttranslational modifications}

The second layer of epigenetic gene regulation resides in the histone proteins around which the DNA double helix is wound. These evolutionarily conserved proteins are comprised of a globular domain and a histone amino-terminal tail. The latter structure, in particular, provides a robust platform for a myriad of posttranslational modifications that can inform gene expression. ${ }^{61,80}$ To date, more than 100 distinct modification sites have been characterized (Table 1) ${ }^{81} \mathrm{~A}$ major challenge of the postgenomic era is to understand their individual and combinatorial effect on gene expression. ${ }^{65,81}$ Examples of well-studied histone posttranslational modifications include lysine acetylation, lysine and arginine methylation, serine and threonine phosphorylation, and lysine ubiquitylation. ${ }^{62,80}$ These marks are mutually exclusive for any given histone amino acid residue. For example, histone 3 lysine 9 (H3K9) can either be acetylated or methylated, but not both.

How do histone posttranslational modifications regulate gene expression? Two general mechanisms are postulated. First, histone posttranslational modifications can alter the physical structure of chromatin and its accessibility to DNAbinding proteins, such as transcriptional regulators. ${ }^{82}$ The best example is histone lysine acetylation, whereby acetyl marks neutralize the basic charge of lysine residues and

Table I Known epigenetic modifications and their effect on gene transcription

\begin{tabular}{ll}
\hline Mechanism & $\begin{array}{l}\text { Transcriptional } \\
\text { effect }\end{array}$ \\
\hline DNA modifications & \\
Methylation (CpG dinucleotides) & $\downarrow$ \\
Hydroxymethylation (CpG dinucleotides) & $?$ \\
Histone posttranslational modifications & \\
Histone H3 & \\
Acetylation (K9, KI4) & $\uparrow$ \\
Methylation & $\uparrow$ \\
$\quad$ K4 & $\downarrow$ \\
$\quad$ K9 & $\downarrow$ \\
$\quad$ K27 & $\downarrow$ \\
$\quad$ K36 & $\uparrow$ \\
Phosphorylation (SI0) & $\uparrow / \downarrow$ \\
Histone H4 & \\
Acetylation (K5, K8, KI2, KI6) & $\uparrow$ \\
Methylation (K20) & $\downarrow$ \\
Long noncoding mRNA (IncRNA) mechanisms & \\
Repressive IncRNAs & \\
eg, Xist, ANRIL, HOTAIR & \\
Activating IncRNAs & \\
eg, HOTTIP & \\
\hline
\end{tabular}

Abbreviations: $\mathrm{K}$, lysine; $\mathrm{S}$, serine. 
thereby prevent the higher-order compaction of chromatin. This conformational change makes chromatin more open and accessible to DNA-binding proteins. ${ }^{83,84}$ More important than the direct physical effect on the structure of chromatin, perhaps, is the regulatory information contained within the specific combinations of histone marks. This mechanistic concept is captured in a hypothesis termed the "histone code," eloquently put forward by Strahl and Allis more than 10 years ago. ${ }^{85}$ At its core, the hypothesis states that a given combination of modifications is "read" by a combination-specific protein or protein complex to effect a specific gene-expression outcome. Given the hundreds of histone-modification sites, there are innumerable combinatorial possibilities. ${ }^{86}$ Cracking the histone code will take years of detailed and systematic studies. It remains a top priority for the epigenetics research community.

Tremendous strides have been made in understanding the impact of specific histone posttranslational modifications in the control of mammalian gene expression. To date, the best-understood histone tail modifications are lysine acetylation and lysine methylation. ${ }^{13,80}$ Each modification is catalyzed by an increasingly well-characterized group of "writers" that can then be interpreted by a distinct group of "readers." For example, in mammalian cells, lysine acetylation is catalyzed by three families of histone acetyltransferases (HATs): GNAT, MYST, and CBP/p300. In general, they have poor specificity for individual histone tail lysine residues, and are targeted to relevant promoters in the context of large, multiprotein complexes. Indeed, the demonstration that classical transcriptional coactivators possess intrinsic HAT activity helped to establish histone lysine acetylation as a permissive, epigenetic mark strongly correlated with transcriptional activation. ${ }^{13,80}$ The removal of histone lysine acetylation is accomplished by four families of histone deacetylases (HDACs): class I (HDAC1-3, HDAC8), class II (HDAC4-7, HDAC9-10), class III sirtuins (SIRT1-7), and class IV (HDAC11). Experimentally, these families of HDACs are further categorized by their sensitivity to inhibition by the pharmacological agent, trichostatin A (TSA). Class I and II HDACs are TSA-sensitive, while class III and IV HDACs are TSA-insensitive. Like HATs, HDACs demonstrate poor specificity for individual lysine residues and are recruited to target promoters in large, multiprotein complexes. This targeting is accomplished by a group of acetyl lysine "readers" that contain a specific protein domain - the bromodomain. ${ }^{13,80}$ Importantly, HDAC inhibitors have found early clinical utility in the treatment of hematological malignancies, in particular, T-cell lymphomas. ${ }^{87}$ Their efficacy in the treatment of solid cancers, ${ }^{88}$ neurodegenerative disease, ${ }^{89}$ and immune-mediated pathologies, ${ }^{90}$ among a myriad of other human ailments, is eagerly being investigated.

Recent studies on histone lysine methylation underscore the tremendous complexity of epigenetic gene regulation. Unlike histone lysine acetylation, the downstream effects of lysine methylation on gene expression are residue-specific and context-dependent. ${ }^{13,80,91}$ For example, histone H3 lysine 4 (H3K4) is strongly associated with transcriptional activation, while $\mathrm{H} 3 \mathrm{~K} 9$ is a classical repressive mark associated with heterochromatin formation and transcriptional silencing. These epigenetic modifications are controlled by distinct groups of readers and writers. Lysine methylation biology is even more finessed. An individual histone lysine residue can be mono-, di-, or trimethylated with profound effects on mammalian gene expression. The functional relevance of these nuanced modifications is supported by their differential localization in the genome; for example, H3K4 monomethylation preferentially localizes to enhancers and $\mathrm{H} 3 \mathrm{~K} 4$ trimethylation to active promoters. ${ }^{13,92}$

In addition to the dizzying complexity of histone posttranslational modifications, more recent studies have established important roles for nucleosome density, ${ }^{93,94}$ adenosine triphosphate-dependent chromatin remodeling, ${ }^{95}$ and the regulated, replication-independent incorporation of histone variants in the control of mammalian gene expression. ${ }^{96}$ For example, across all eukaryotic species, promoters and enhancers are more nucleosome-depleted than transcribed regions. Moreover, this state of relative histone depletion is dynamic and correlated with gene expression. ${ }^{97}$ These additional layers of epigenetic control provide an intricate and responsive system superimposed on the static genetic code.

\section{RNA-based mechanisms}

The central dogma of genetics states that DNA is transcribed to mRNA, which is in turn translated into proteins. However, the discovery of an extensive catalog of long RNA transcripts that do not code for proteins - lncRNAs provides a new perspective on the importance of RNA in gene regulation (Figure 3). ${ }^{37,98}$ Of the three general modes of epigenetic regulation, RNA-based mechanisms are the most recently described and presently the least well understood. It is a matter of argument whether microRNAs fall into the definition of epigenetic regulation. They are considered by some to be epigenetic modifiers. Though not the focus of this review, readers are directed to work that has shown the involvement of microRNAs in gene regulation. ${ }^{99,100}$ MicroRNAs can exert an effect on gene transcription. For example, 


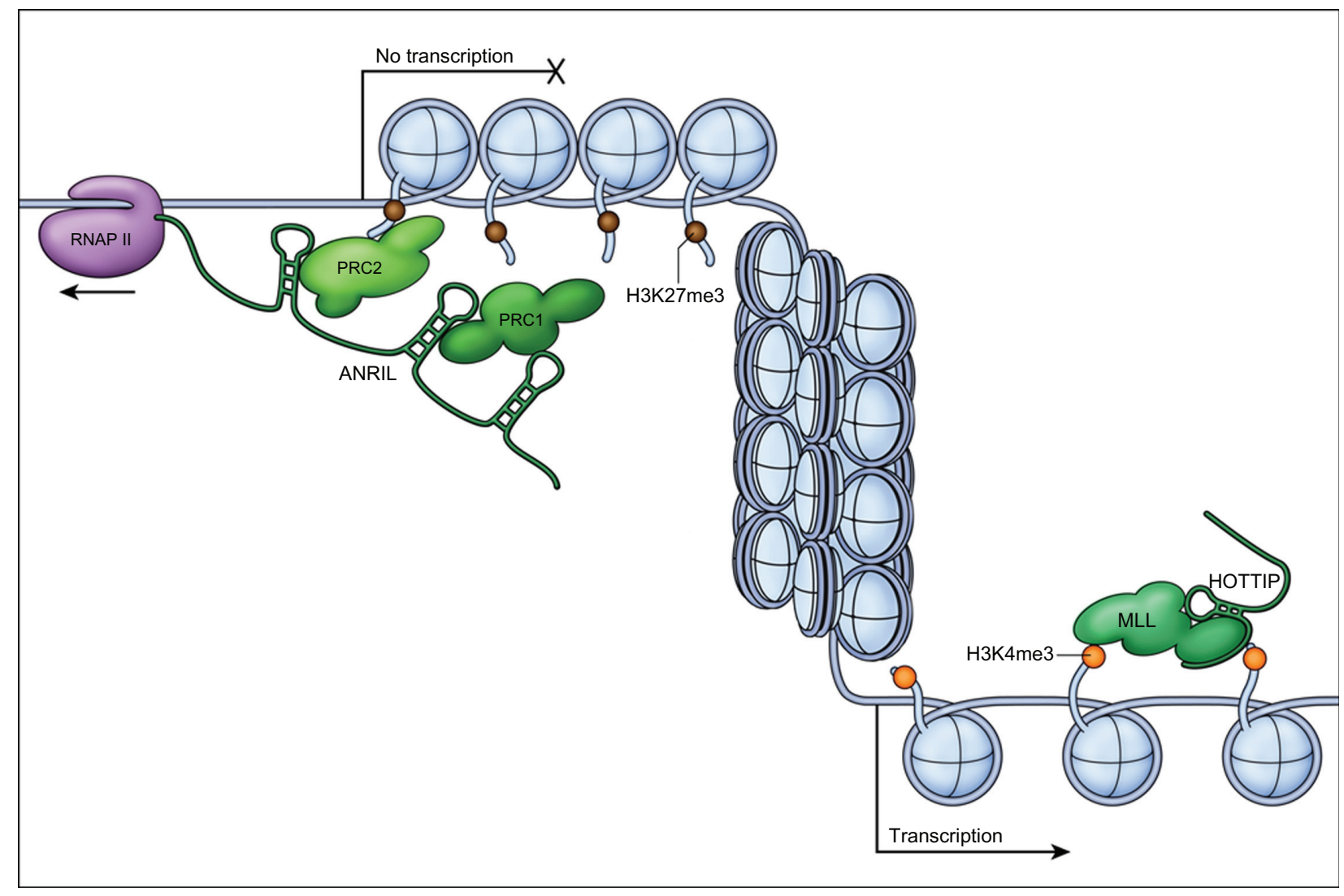

Figure 3 Long noncoding RNAs (IncRNAs) can act in cis or trans to activate or repress gene transcription through modification of chromatin.

Notes: In cis, the IncRNA is transcribed and recruits chromatin-modifying complexes to the site of transcription. For example, antisense noncoding RNA in the INK4 locus (ANRIL) recruits PRC2, which serves to repress the transcription of adjacent genes that have histones with the mark H3K27me3. In trans, IncRNAs act at a distal location from their transcription site, where they interact with target genes and chromatin-modifying complexes. The IncRNA HOTTIP acts at distal HoxA genes and interacts with the histone methyltransferase MLL to mediate the addition of trimethylation on lysine 4 of histone $\mathrm{H} 3(\mathrm{H} 3 \mathrm{~K} 4 \mathrm{me} 3)$ to activate transcription.

DNA methylation states of the E-cadherin gene can be modified by RNA interference. ${ }^{99}$ This miRNA field will also be exciting to follow given their emerging role in the pathophysiology of stroke. ${ }^{101}$ As there are interesting overlaps between predominantly posttranscriptional regulators (eg, microRNAs) and transcription factors, similar overlaps in pathways are expected for epigenetic regulators, and readers are directed to a review in their role in various aspects of stroke. ${ }^{101,102}$ Amongst others, RNA-based mechanisms of epigenetic gene regulation can involve the coordinated activities of lncRNAs with other epigenetic activities, such as DNA methylation and histone posttranslational modifications. ${ }^{103}$ These lncRNAs are functionally distinct from small noncoding RNAs, such as microRNAs, that primarily mediate posttranscriptional repression in the cytoplasm. In mammalian systems, the most studied lncRNA is the $17-\mathrm{kb}$ Xist nuclear RNA, which is expressed exclusively from the inactivated $\mathrm{X}$ chromosome (Xi) in women, and is essential for silencing one of the $\mathrm{X}$ chromosomes in somatic female mammalian cells. ${ }^{104}$
Using chromatin-state maps, actively transcribed genes show unique signatures of $\mathrm{H} 3 \mathrm{~K} 4$ trimethylation at promoters and $\mathrm{H} 3 \mathrm{~K} 36$ trimethylation within transcribed regions, now termed K4-K36 domains. ${ }^{105}$ Using these K4-K36 domains to demarcate transcriptional units has led to the identification of thousands of lncRNAs in mammalian cells with broad cellular functions. ${ }^{106}$ The discovery and action of lncRNAs are an evolving story, as their cataloging and functions continue to expand. Initially, approximately 1600 lncRNAs were identified and current studies have expanded that to more than 8000 lncRNAs. Since the initial reports of the first lncRNAs in 2008 and 2009, emphasis has been placed on defining their functional interactions with chromatin-modifying complexes rather than their location with respect to other genes. ${ }^{107}$

lncRNAs have been shown to direct both repressive and activating complexes and allow chromatin modifications to occur at specific loci (Figure 3). ${ }^{56,60,108}$ One such lncRNA, HOTAIR, was found to regulate the expression of developmental HOX genes, and has been implicated in promoting the invasiveness and metastasis of breast cancer. ${ }^{38,109}$ 
HOTAIR functions in HOXD silencing by recruiting polycomb repressive complex 2 (PRC2) and its $\mathrm{H} 3 \mathrm{~K} 27$ trimethylation activity. ${ }^{109}$ The mechanism of how this directing occurs remains unclear. Although these RNAs were initially identified as long intergenic noncoding RNAs, this concept has become broadened to encompass lncRNAs that may exist near or antisense to protein-coding genes. ANRIL is an example of an IncRNA, as it is antisense to protein-coding genes but interacts with the chromatin-modifying complexes PRC1 and PRC2 to repress the target loci (see below). ${ }^{56,110}$ Additionally, lncRNAs can mediate transcriptional activation via recruitment of the $\mathrm{H} 3 \mathrm{~K} 4$ methyltransferase MLL1. One intriguing model is HOTTIP that acts at distal HOXA genes to activate transcription by mediating $\mathrm{H} 3 \mathrm{~K} 4$ trimethylation. ${ }^{108}$ Additional examples of lncRNA in mammals include $A I R$ and $K C N Q 1 O T 1$, which are involved in genomic imprinting, a process that mediates the expression of only one allele of a gene in a parent-of-origin-dependent manner.

It is clear that the clinical implications and the basic science discovery of lncRNAs are just emerging. A hint to their biological relevance, especially in the pathophysiology of stroke, may be found in unbiased GWAS results. GWAS hits also fall into large "gene deserts," genomic regions with no protein-coding genes that are not artifacts and may have functional importance in complex disease. This is interesting given that approximately $80 \%$ of SNPs exist within intergenic and noncoding intronic regions, which make up a significant proportion of GWAS hits. ${ }^{111}$ The possibility that a gene can be implicated in the genetic cause of disease because it produces a functional RNA that is an epigenetic modifier is an emerging concept.

\section{An epigenetic theory of complex, non-Mendelian disease}

These epigenetic effectors are more than novel regulators of gene expression, but provide for a fundamentally different perspective on common human diseases, like stroke, with apparently strong genetic and environmental components. Epigenetics sits at the interface between the static genetic code and ever-changing environment with potentially longstanding influences on gene expression and inherited disease susceptibility. It provides a molecular framework for studying gene-environment interactions and thereby opens new avenues for greater understanding of human diseases and their treatment. Fundamental to this epigenetic perspective is the duality of the epigenetic code as both a dynamic and responsive landscape to environmental change and a potential carrier of heritable information. ${ }^{12-14,55}$
Is there evidence to suggest that the discordance of $\mathrm{MZ}$ twins for stroke liability or the phenotypic variability of family members with CADASIL are determined by epigenetic mechanisms? The short answer is "maybe." In 2005, Fraga et al performed an elegant experiment assaying for three epigenetic marks (DNA methylation and histone H3 and $\mathrm{H} 4$ acetylation) in 40 twin pairs of varying ages. ${ }^{12}$ Those MZ twins that demonstrated the greatest intra-twin epigenetic differences were older, spent more of their lifetime apart, and reported the largest differences in medical health. These data suggest that epigenetic differences can accrue over time and account for phenotypic differences, such as disease expression, later in life. An analogous observation is made in genetically identical mammals cloned by somatic cell nuclear transfer. While some offspring are phenotypically normal, a majority are runted, a phenomenon at least partially explained by the inefficient epigenetic reprogramming of transplanted nuclei. ${ }^{113}$ These data are compelling.

And what of the missing heritability of GWASs? If an epigenetic explanation could account for this missing heritability, there would have to be evidence for transgenerational inheritance of an epimutation. Although this concept remains contentious and hotly debated, these data are accruing in animal models, ${ }^{114}$ with a few notable examples in man. ${ }^{55,115-117}$

Epigenetic theory encompasses molecular pathways that regulate the structure and accessibility of chromatin without changing the genetic code. The three main effectors of epigenetics are DNA methylation, histone density and posttranslational modifications, and RNA-based mechanisms, such as lncRNAs. In the next section, we illustrate and discuss the roles of these three effector pathways using case studies of two genes endothelial nitric oxide synthase (eNOS) and ANRIL. eNOS is a protein-coding gene that is regulated by epigenetics, while ANRIL is an IncRNA that mediates epigenetic regulation.

\section{Case study I eNOS: from molecular cloning to a model of vascular epigenetic gene regulation}

Given that endothelial cells (ECs) figure prominently in the pathophysiology of large-vessel atherosclerosis, it is important to understand how gene expression in these cells becomes perturbed in disease (Figure 4). We do not discount the contribution of other pathophysiological factors beyond blood-vessel pathology, especially the coagulation pathway, complement, and platelets, among others. Indeed, the involvement of genetic and epigenetic influences in these complementary events has been well argued. ${ }^{118,119}$ The eNOS/NOS3 gene is very restricted in expression to ECs, where it provides the dominant source 


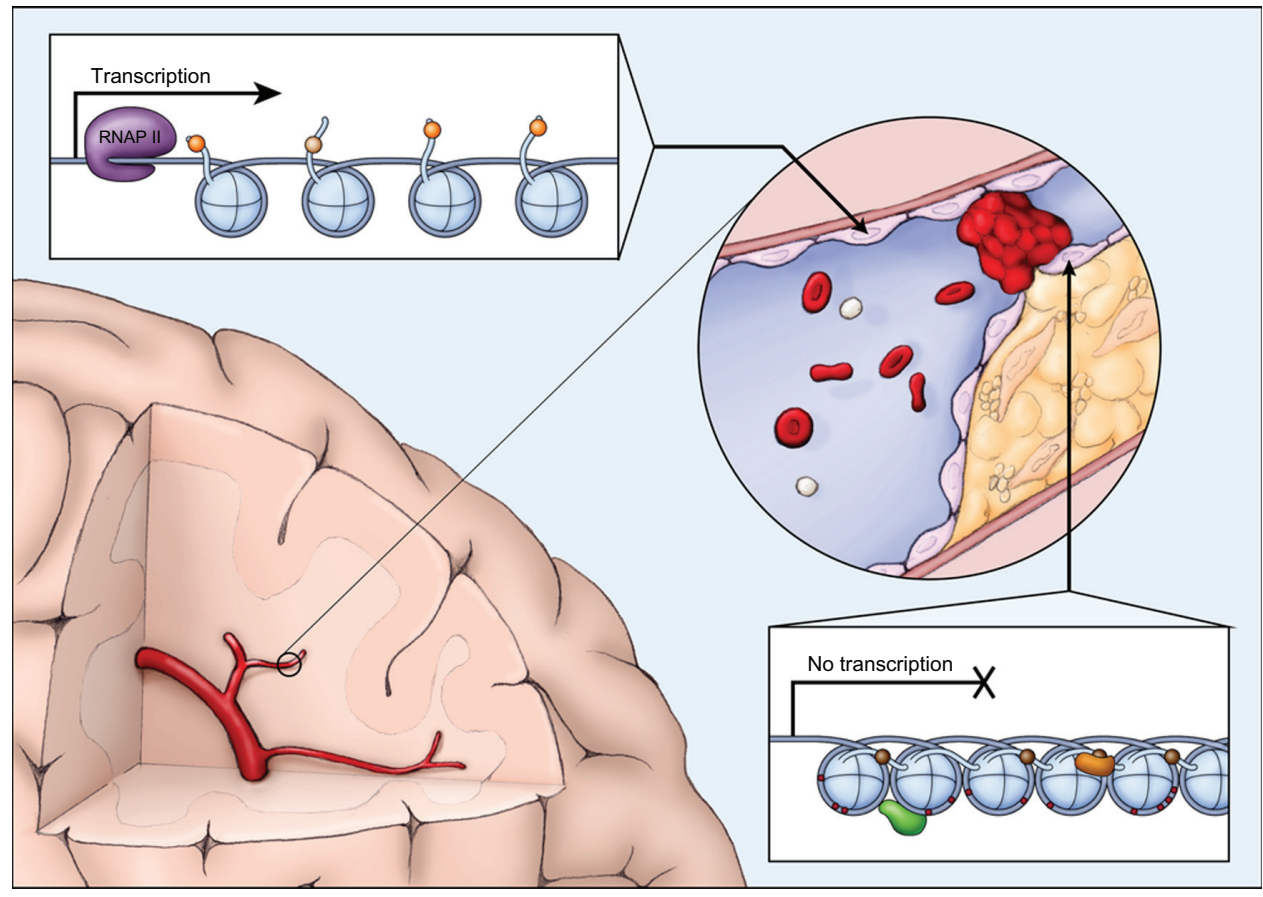

Figure 4 Large-vessel occlusion is a mechanism of ischemic stroke where epigenetics may play a role.

Notes: Proper gene expression in endothelial cells in healthy vasculature maintains an antithrombotic and antiatherogenic cellular phenotype. An open chromatin configuration would allow transcription of genes, such as the expression of eNOS, in healthy endothelium. In contrast, a dysfunctional endothelium could be characterized by a closed chromatin configuration with repressive epigenetic profile. Endothelial cells that overlay atherosclerotic plaques become dysfunctional and exhibit changes in gene expression, which may be mediated by changes in chromatin accessibility.

of nitric oxide in the vasculature. Nitric oxide is a vasodilator that plays a vital role in the maintenance of vascular homeostasis, by the virtue of potent antithrombotic and antiatherogenic activities. The generation of nitric oxide by nitric oxide synthases maintains the vasculature in the vessels of the brain to inhibit ischemic or hemorrhagic stroke. It does so via the inhibition of platelet aggregation and leukocyteendothelium adhesion, inducing vasodilation and decreasing VSMC proliferation. ${ }^{120} \mathrm{~A}$ large facet of stroke pathology is the attenuation of large vessels caused by atherosclerosis; therefore, it is important to understand changes in $e N O S$ regulation during endothelial dysfunction. ${ }^{1}$ For example, eNOS mRNA and protein levels are decreased in endothelial cells overlying atherosclerotic plaques. ${ }^{121,122}$ Seminal work in dyslipidemia, a risk factor for stroke, has shown strong evidence that lowdensity lipoprotein levels play a key role in the induction of atherosclerotic lesions and decreased nitric oxide availability. ${ }^{123}$ Changes in eNOS expression occur at characteristic locations in the vasculature due to changes in local hemodynamic forces, such as the curvature of the aorta and branch points. ${ }^{124}$ Examination of the mouse aorta at regions predisposed to atherosclerosis shows decreased eNOS activity and an increase in priming of the nuclear factor kappa B signal-transduction cascade. ${ }^{125,126}$ The regulation of vascular homeostasis is subject to nitric oxide availability through contributions of eNOS, the expression of which is abnormal in disease.

Studies conducted in vivo have shown that deregulation of eNOS contributes to vessel attenuation and also contributes to postinfarction pathology. Studies have shown that eNOS-deficient mice show decreased neovascularization, larger infarcts, and smaller penumbral regions, although the mechanisms of how this occurs are still unclear. ${ }^{127,128}$ This contrasts with studies done in neuronal NOS (nNOS)deficient mice. $n N O S^{-/-}$mice show smaller cerebral infarctions, although blood flow is equivalent in $n N O S$ knockout and wild-type mice. This suggests a potential role for $n N O S$, but not eNOS, in tissue damage after cerebral ischemia. ${ }^{129}$ Clearly, the $n N O S$ gene is relevant to global hypoxia and anemia-induced cerebral hypoxia, as recently shown by Tsui and colleagues. ${ }^{130}$ Deficiencies in the inducible form of NOS - iNOS - have revealed no changes in infarction size after cerebral ischemia. Interestingly, $i N O S$ shows changes in mRNA splicing after infarction as differential expression of exons 2 and 3 are seen. ${ }^{131}$ It remains unclear as to the functional effects of these changes.

In humans, there are a number of EC-enriched genes in addition to eNOS, such as von Willebrand factor $(V W F)$, $C D 31$, vascular endothelial growth factor 2 (VEGFR2), 
and intercellular adhesion molecule 2 (ICAM2), among others. However, no master transcriptional control factor has been found in endothelial cells. Although some trans factors are relatively EC-enriched, such as ETS and GATA factors, these factors alone cannot explain the EC-enriched expression of these target genes. This contrasts with other terminally differentiated adult cell types that have master transcription-factor regulators, such as PPARG and MYOD, in adipocytes and skeletal muscle cells, respectively. ${ }^{132,133}$ Thus, the typical cis/ trans paradigms may not be applicable to the restricted gene expression in EC. Epigenetic regulation has provided an interesting explanation of cell-specific expression in endothelial cells, particularly through the study of eNOS. ${ }^{12}$

Molecular characterization of the eNOS gene started with its cloning, which revealed a protein-coding unit with 26 exons spanning $21 \mathrm{~kb}$ of genomic DNA that produces a 4052-nucleotide mRNA. ${ }^{134-136}$ The eNOS promoter does not contain a TATA box or a $\mathrm{CpG}$ island, but it does contain two regulatory domains termed positive regulatory domains I and II at -104/-95 and -144/-115, respectively, relative to the transcription start site. The eNOS promoter contains cis binding sites for the Ets family members, GATA, SP1, AP-1, and YY1, which are common between endothelial enriched genes. ${ }^{137}$ Remarkably, these transcription factors are not endothelial-restricted, in contrast to eNOS expression. The finding that only nonendothelial restricted transcription factor-binding sites were detected at the promoter of eNOS is an important clue that the simplistic view that cis/trans interactions may not suffice for endothelial gene enrichment.

The initial discovery of the role of epigenetics in eNOS gene expression came from the use of episomal eNOS promoter-reporter constructs. These constructs showed in vitro activity regardless of cell type while native eNOS mRNA was EC-enriched. ${ }^{138}$ In contrast, stably integrated eNOS promoter-reporter transgenic mice recapitulated eNOS expression patterns in humans. ${ }^{139,140}$ Since the expression of the eNOS promoter reporter in transgenic mice is dependent on the chromatin structure of its integrated site, this suggests that epigenetics plays a role in the endothelial-enriched expression of eNOS. Indeed, the first direct evidence of eNOS epigenetic regulation is DNA methylation. DNA methylation plays a role in eNOS transcription, as suggested by the finding that the eNOS promoter showed DNA hypomethylation in ECs, but dense methylation in nonexpressing cells, such as VSMCs. ${ }^{138}$ DNA methylation abrogated synergistic binding of Sp1, Sp3, and Ets 1 to the eNOS promoter. Moreover, recovery of eNOS expression was observed in HeLa cells and VSMCs after treatment with the DNA methylation inhibitor 5-azacytadine. ${ }^{138}$
Additional studies of epigenetic mechanisms indicated that the histone code plays an active role in the proper function of the eNOS gene in ECs. Interrogation of various histone marks at the eNOS promoter showed the presence of acetyl $\mathrm{H} 3$ and H4 marks and trimethylated lysine 4 of H3, specifically H3K9 and H4K12, which are hallmarks of actively transcribed chromatin in ECs (Table 1). In contrast, non-ECs lacked these histone posttranslational modifications. Indeed, repression of eNOS in non-ECs is abrogated by the addition of trichostatin A, a histone deacetylase inhibitor. ${ }^{141}$ Taken together, eNOS expression is regulated, in part, by epigenetics. Thus, it follows that epigenetics may play a role in disease pathology where eNOS expression is perturbed.

Does the environment affect gene expression in ECs via epigenetic pathways? Newer evidence suggests this may be the case. eNOS mRNA and protein decreases in hypoxic cells; both in vitro and in vivo. ${ }^{142}$ In acute hypoxia, the eNOS promoter shows a decrease in histone-activating marks such as acetylation and lysine-4 methylation, which is mediated by the loss of histone proteins due to histone eviction. Under chronic hypoxia, the histone octamers return to normal levels, but are not modified by the activating marks, that are observed under normoxic conditions. ${ }^{94}$ It is worth highlighting that hypoxia upregulated the expression of an antisense eNOS gene, sONE (eNOS antisense, NOS3AS) that regulates eNOS expression post-transcriptionally. ${ }^{143}$ Little is known about this noncoding gene. The $S O N E$ gene overlaps the $3^{\prime}$ end of the eNOS gene and appears to regulate $e N O S$ mRNA through a posttranscriptional mechanism, different from that of the antisense gene ANRIL (see below).

Overall, eNOS is a remarkable case study of the fundamentals of epigenetic regulation. In a quiescent endothelium, eNOS regulation is maintained by several aspects of epigenetics, while it can change during disease states. Moreover, this gene provides valuable insight into an epigenetic framework that can help to explain the heritability of complex diseases such as ischemic stroke. The non-Mendelian inheritance of atherosclerosis and stroke together with the contribution of $e N O S$ gene regulation argues that epigenetics can be a participant in stoke burden.

\section{Case study 2}

\section{ANRIL: a long noncoding RNA and epigenetic risk stratification in large-vessel ischemic stroke}

ANRIL was first identified by a germ-line deletion in a melanoma-neural system tumor family in an unrelated 
discovery of the $I N K / A R F$ locus. ${ }^{144}$ This discovery happened only months prior to the identification of a coronary artery disease $(\mathrm{CAD})$ risk locus in the genomic region that traverses the ANRIL lncRNA. Four independent groups reported this genetic association. ${ }^{145-148}$ This CAD risk locus sits in a region that is devoid of protein-coding genes, but is located within the $3^{\prime}$ end of the ANRIL gene. The identification of a CAD risk locus spurred investigations into a potential association with stroke due to the cardiovascular-related phenotype. In 2008, Bilguvar and colleagues were the first to identify an association of intracranial aneurysm and an SNP located on chr9p21 within the ANRIL locus. ${ }^{149}$ Although further examination of associations between stroke and this risk locus showed conflicting results, Anderson et al established the likely basis for this confusion by demonstrating that chr9p21 variants are risk factors for ischemic stroke related to large-artery atherosclerosis but not other pathomechanistic stroke subtypes. ${ }^{26}$ Furthermore, a meta-analysis of one SNP (rs10757274) within the locus showed an association with ischemic stroke with a modest effect size (OR, 1.11 [95\% CI, 1.05-1.17, $P=0.0001]) .{ }^{26}$ Moreover, it is expressed in tissues and cell types relevant to stroke, such as adult human brain tissue and blood vessels (endothelial cells, vascular smooth muscle cells), making it a prime candidate for involvement in cardiovascular disease, but full functional analysis remains to be performed. ${ }^{146,150-152}$ Knockdown of the ANRIL IncRNA in vascular smooth-muscle cells has been recently demonstrated to have a profound effect on gene expression in this cell type. ${ }^{151}$ Moreover, epigenetic mediators are being tested as potential targets for therapy in stroke. Readers are referred to recent reviews discussing these findings. ${ }^{153,154}$ Taken together, the evidence suggests that the chr9p21 haplotype influences stroke risk.

During large-scale GWASs at chr9p21 for stroke associations, molecular analysis was conducted on the ANRIL lncRNA transcript. The study of the RNA was elusive due to complexities in its splicing. ANRIL RNA has been found to form multiple rare variants from alternative splicing. Additionally, these variants showed linear and circular forms. ${ }^{150}$ Subsequent studies suggest that ANRIL functions through the $c$ is recruitment of chromatin-modifying complexes - specifically, PRC1 and PRC2 - to neighboring genes of the INK4b/ARF/INK4a locus. This locus spans approximately $42 \mathrm{~kb}$ on human chromosome $9 \mathrm{p} 21$ and is an important regulator of cellular senescence. These genes act through the regulation of retinoblastoma protein, cyclindependent kinases, and p53 signaling. ${ }^{155}$ Regulation of this locus is mediated by $\mathrm{H} 3 \mathrm{~K} 27$ trimethylation catalyzed by
PRC2 and recognized by PRC1 that results in silencing of transcription. ${ }^{37} \mathrm{PRC} 1$ and $\mathrm{PRC} 2$ are recruited to the locus by the lncRNA $A N R I L$, expressed antisense to $A R F / I N K 4 b .{ }^{150}$ It is believed that $A N R I L$ transcription and secondary RNA structure formation are able to interact and direct PRC1 and PRC2 to the adjacent $I N K 4 / A R F$ locus to mediate the establishment of repressive marks H2AK119 and H3K27me3, respectively (Figure 3). ${ }^{56,110}$ The presence of these epigenetic marks is associated with chromatin compaction and transcriptional repression of these protein-coding genes. ${ }^{62}$ More importantly, the previously discussed SNP appears to play a molecular role in ANRIL function. ANRIL alleles harboring the disease-associated SNP are associated with a reduction in $I N K 4 b, I N K 4 a$, and $A R F$ mRNAs. ${ }^{71}$ One theory is that the presence of the disease-associated SNP allele changes the abundance or function of $A N R I L$ splice variants, resulting in their reduced ability to exert full repression on the INK4/ ARF locus. ${ }^{56,110,150}$ This work suggests that SNPs within the risk locus may play a role in $A N R I L$ function.

ANRIL has become a model for the role of epigenetics in complex, non-Mendelian diseases such as stroke, and CAD in general. Although we are far from a complete understanding of $A N R I L$ function in stroke, it is of great interest that this epigenetic modifier represents an exciting newer perspective on stroke pathophysiology.

\section{Concluding remarks: the emerging field of stroke epigenetics}

This review has primarily considered the potential of epigenetic pathways to better understand stroke liability, both inherited and as the result of environmental exposures. A related field of study has emerged that focuses on the role of epigenetic pathways in response to cerebral ischemia and their modulation as novel targets for therapeutic intervention. For example, Endres et al have demonstrated increased levels of DNA methylation after ischemia/reperfusion in a mouse model of mild focal brain ischemia. ${ }^{156,157}$ Genetic reduction of DNMT levels and treatment with a pharmacological DNMT inhibitor were neuroprotective. However, this neuroprotective effect was not observed in severe stroke/excitotoxic cell death, underscoring the complexity of these pathways. Similar studies have investigated histone acetylation pathways in rodent models of focal cerebral ischemia. ${ }^{158-16}$ These studies highlighted the potential of pharmacological HDAC inhibitors to serve as powerful neuroprotective agents, and were recently reviewed by Langley et al. ${ }^{153}$ Less well studied but equally compelling is the role of noncoding RNAs in ischemic stroke pathogenesis. ${ }^{162,163}$ While the use of 
epigenetic modifiers in ischemic stroke is enticing, caution is warranted, as our understanding of these mechanisms is still in its infancy. ${ }^{36}$ The interested reader is referred to an excellent three-part review by Qureshi and Mehler on the emerging role of epigenetics in stroke pathogenesis. ${ }^{164-166}$ Finally, it must be noted that ischemic stroke pathogenesis is complex and multifactorial, implicating a diversity of cell types and molecular processes. While we have focused on vascular-wall pathology in this review, epigenetic concepts also apply to other facets of ischemic stroke pathogenesis, eg, platelet aggregation, thrombus formation, and cholesterol homeostasis. These topics are beyond the scope of this manuscript and expertly reviewed elsewhere. ${ }^{118,167}$

Epigenetic pathways offer a new perspective in the control of gene regulation with relevance to human cardiovascular disease and stroke research. As epigenetic processes are dynamic and respond to environmental cues, they provide the molecular substrate for understanding and experimentally verifying geneenvironment interactions. The observation that a large number of GWAS hits fall within regions of the genome without classical coding function highlights the importance of epigenetics in human disease, including stroke. The ANRIL case is the best example of this phenomenon in human cardiovascular disease. Valuable insight has also been gained by studies exploring the epigenetic regulation of the $e N O S$ gene in response to physiological and pathophysiological stimuli, including hypoxia. As we expand our understanding of epigenetics, the hope is that newer insight will be gained in prevention, diagnosis, and treatment of stroke. This is important because of its implications for clinical diagnosis and therapeutic intervention in vascular diseases, especially in large-vessel ischemic stroke.

\section{Acknowledgments}

We gratefully thank members of the Marsden lab for critical review of the manuscript. Philip Marsden holds the Keenan Chair in Medical Research and is supported by operating grants from CIHR MOP 79475 and NIH/HHLBI P01 HL076540-06A1. Charles Matouk gratefully acknowledges support from Yale University, jointly from the School of Medicine and Department of Neurosurgery, and the Brain Tumor Gift Fund.

\section{Disclosure}

The authors report no conflicts of interest in this work.

\section{References}

1. Roger VL, Go AS, Lloyd-Jones DM, et al. Heart disease and stroke statistics - 2012 update: a report from the American Heart Association. Circulation. 2012;125(1):e2-e220.
2. Heidenreich PA, Trogdon JG, Khavjou OA, et al. Forecasting the future of cardiovascular disease in the United States: a policy statement from the American Heart Association. Circulation. 2011;123(8): 933-944.

3. Di Carlo A. Human and economic burden of stroke. Age Ageing. 2009; 38(1):4-5.

4. Strong K, Mathers C, Bonita R. Preventing stroke: saving lives around the world. Lancet Neurol. 2007;6(2):182-187.

5. Lopez AD, Mathers CD, Ezzati M, Jamison DT, Murray CJ. Global and regional burden of disease and risk factors, 2001: systematic analysis of population health data. Lancet. 2006;367(9524):1747-1757.

6. Johnston SC, Mendis S, Mathers CD. Global variation in stroke burden and mortality: estimates from monitoring, surveillance, and modelling. Lancet Neurol. 2009;8(4):345-354.

7. Feigin VL, Lawes CM, Bennett DA, Barker-Collo SL, Parag V. Worldwide stroke incidence and early case fatality reported in 56 populationbased studies: a systematic review. Lancet Neurol. 2009;8(4): 355-369.

8. Warlow C, van Gijn J, Dennis M, et al. Stroke: Practical Management. 3rd ed. Oxford: Blackwell Publishing; 2008:39-40.

9. Adams HP Jr, Bendixen BH, Kappelle LJ, et al. Classification of subtype of acute ischemic stroke. Definitions for use in a multicenter clinical trial. TOAST. Trial of Org 10172 in Acute Stroke Treatment. Stroke. 1993;24(1):35-41.

10. Meschia JF, Worrall BB, Rich SS. Genetic susceptibility to ischemic stroke. Nat Rev Neurol. 2011;7(7):369-378.

11. Lanktree MB, Dichgans M, Hegele RA. Advances in genomic analysis of stroke: what have we learned and where are we headed? Stroke. 2010;41(4):825-832.

12. Yan MS, MatoukCC, Marsden PA. Epigenetics of the vascularendothelium. J Appl Physiol. 2010;109(3):916-926.

13. Matouk CC, Marsden PA. Epigenetic regulation of vascular endothelial gene expression. Circ Res. 2008;102(8):873-887.

14. Shirodkar AV, Marsden PA. Epigenetics in cardiovascular disease. Curr Opin Cardiol. 2011;26(3):209-215.

15. Rubattu S, Volpe M, Kreutz R, Ganten U, Ganten D, Lindpaintner K. Chromosomal mapping of quantitative trait loci contributing to stroke in a rat model of complex human disease. Nat Genet. 1996;13(4): 429-434.

16. Barone FC, Knudsen DJ, Nelson AH, Feuerstein GZ, Willette RN. Mouse strain differences in susceptibility to cerebral ischemia are related to cerebral vascular anatomy. J Cereb Blood Flow Metab. 1993;13(4): 683-692.

17. Majid A, He YY, Gidday JM, et al. Differences in vulnerability to permanent focal cerebral ischemia among 3 common mouse strains. Stroke. 2000;31(11):2707-2714.

18. Lambertsen KL, Gregersen R, Finsen B. Microglial-macrophage synthesis of tumor necrosis factor after focal cerebral ischemia in mice is strain dependent. J Cereb Blood Flow Metab. 2002;22(7): 785-797.

19. Keum S, Marchuk DA. A locus mapping to mouse chromosome 7 determines infarct volume in a mouse model of ischemic stroke. Circ Cardiovasc Genet. 2009;2(6):591-598.

20. Dichgans M. Genetics of ischaemic stroke. Lancet Neurol. 2007;6(2): 149-161.

21. Seshadri S, Beiser A, Pikula A, et al. Parental occurrence of stroke and risk of stroke in their children: the Framingham study. Circulation. 2010; 121(11):1304-1312.

22. Bevan S, Markus HS. Genetics of common polygenic ischaemic stroke: current understanding and future challenges. Stroke Res Treat. 2011;2011:179061.

23. Duggirala R, Gonzalez Villalpando C, O'Leary DH, Stern MP, Blangero J. Genetic basis of variation in carotid artery wall thickness. Stroke. 1996;27(5):833-837.

24. Moskau S, Golla A, Grothe C, Boes M, Pohl C, Klockgether T. Heritability of carotid artery atherosclerotic lesions: an ultrasound study in 154 families. Stroke. 2005;36(1):5-8. 
25. Jartti L, Ronnemaa T, Kaprio J, et al. Population-based twin study of the effects of migration from Finland to Sweden on endothelial function and intima-media thickness. Arterioscler Thromb Vasc Biol. 2002;22(5):832-837.

26. Anderson CD, Biffi A, Rost NS, Cortellini L, Furie KL, Rosand J. Chromosome 9p21 in ischemic stroke: population structure and metaanalysis. Stroke. 2010;41(6):1123-1131.

27. Holdt LM, Teupser D. Recent studies of the human chromosome 9p21 locus, which is associated with atherosclerosis in human populations Arterioscler Thromb Vasc Biol. 2012;32(2):196-206.

28. Bellenguez C, Bevan S, Gschwendtner A, et al. Genome-wide association study identifies a variant in HDAC9 associated with large vessel ischemic stroke. Nat Genet. 2012;44(3):328-333.

29. Holliday EG, Maguire JM, Evans TJ, et al. Common variants at 6p21.1 are associated with large artery atherosclerotic stroke. Nat Genet. 2012;44(10):1147-1151.

30. Noh KM, Hwang JY, Follenzi A, et al. Repressor element-1 silencing transcription factor (REST)-dependent epigenetic remodeling is critical to ischemia-induced neuronal death. Proc Natl Acad Sci USA. 2012;109(16):E962-E971.

31. Skowronski K, Dubey S, Rodenhiser D, Coomber B. Ischemia dysregulates DNA methyltransferases and p16INK4a methylation in human colorectal cancer cells. Epigenetics. 2010;5(6):547-556.

32. van Loo KM, Schaub C, Pernhorst K, et al. Transcriptional regulation of T-type calcium channel CaV3.2: bi-directionality by early growth response 1 (Egr1) and repressor element 1 (RE-1) protein-silencing transcription factor (REST). J Biol Chem . 2012;287(19):15489-15501.

33. Bithell A. REST: transcriptional and epigenetic regulator. Epigenomics. 2011;3(1):47-58.

34. Formisano L, Noh KM, Miyawaki T, Mashiko T, Bennett MV, Zukin RS. Ischemic insults promote epigenetic reprogramming of mu opioid receptor expression in hippocampal neurons. Proc Natl Acad Sci USA. 2007;104(10):4170-4175.

35. Grimm D, Streetz KL, Jopling CL, et al. Fatality in mice due to oversaturation of cellular microRNA/short hairpin RNA pathways. Nature. 2006;441(7092):537-541.

36. Marsden PA. RNA interference as potential therapy - not so fast. N Engl J Med. 2006;355(9):953-954.

37. Martin L, Chang HY. Uncovering the role of genomic "dark matter" in human disease. J Clinical Invest. 2012;122(5):1589-1595.

38. Gupta RA, Shah N, Wang KC, et al. Long non-coding RNA HOTAIR reprograms chromatin state to promote cancer metastasis. Nature. 2010;464(7291):1071-1076.

39. Petronis A. Epigenetics and twins: three variations on the theme. Trends Genet. 2006;22(7):347-350.

40. Poulsen P, Esteller M, Vaag A, Fraga MF. The epigenetic basis of twin discordance in age-related diseases. Pediatr Res. 2007;61(5 Pt 2): 38R-42R.

41. Bak S, Gaist D, Sindrup SH, Skytthe A, Christensen K. Genetic liability in stroke: a long-term follow-up study of Danish twins. Stroke. 2002;33(3):769-774.

42. Brass LM, Isaacsohn JL, Merikangas KR, Robinette CD. A study of twins and stroke. Stroke. 1992;23(2):221-223.

43. Chabriat H, Joutel A, Dichgans M, Tournier-Lasserve E, Bousser MG Cadasil. Lancet Neurol. 2009;8(7):643-653.

44. Ayata C. CADASIL: experimental insights from animal models. Stroke. 2010;41(Supp1 10):S129-S134.

45. Dichgans M, Mayer M, Uttner I, et al. The phenotypic spectrum of CADASIL: clinical findings in 102 cases. Ann Neurol. 1998;44(5): 731-739.

46. Opherk C, Peters N, Holtmannspotter M, Gschwendtner A, MullerMyhsok B, Dichgans M. Heritability of MRI lesion volume in CADASIL: evidence for genetic modifiers. Stroke. 2006;37(11):2684-2689.

47. Adib-Samii P, Brice G, Martin RJ, Markus HS. Clinical spectrum of CADASIL and the effect of cardiovascular risk factors on phenotype: study in 200 consecutively recruited individuals. Stroke. 2010;41(4):630-634.
48. Mykkanen K, Junna M, Amberla K, et al. Different clinical phenotypes in monozygotic CADASIL twins with a novel NOTCH3 mutation. Stroke. 2009;40(6):2215-2218.

49. Mykkanen K, Savontaus ML, Juvonen V, et al. Detection of the founder effect in Finnish CADASIL families. Eur J Hum Genet. 2004; 12(10):813-819.

50. Hardy J, Singleton A. Genomewide association studies and human disease. N Engl J Med. 2009;360(17):1759-1768.

51. Manolio TA, Collins FS, Cox NJ, et al. Finding the missing heritability of complex diseases. Nature. 2009;461(7265):747-753.

52. Visscher PM. Sizing up human height variation. Nat Genet. 2008;40(5) 489-490.

53. Perola M. Genetics of human stature: Lessons from genome-wide association studies. Horm Res Paediatr. 2011;76 Suppl 3:10-11.

54. Gibson G. Rare and common variants: twenty arguments. Nat Rev Genet. 2011;13(2):135-145.

55. Petronis A. Epigenetics as a unifying principle in the aetiology of complex traits and diseases. Nature. 2010;465(7299):721-727.

56. Yap KL, Li S, Munoz-Cabello AM, et al. Molecular interplay of the noncoding RNA ANRIL and methylated histone H3 lysine 27 by polycomb CBX7 in transcriptional silencing of INK4a. Mol Cell. 2010;38(5):662-674.

57. Lanktree MB, Hegele RA, Yusuf S, Anand SS. Multi-ethnic genetic association study of carotid intima-media thickness using a targeted cardiovascular SNP microarray. Stroke. 2009;40(10):3173-3179.

58. Finishing the euchromatic sequence of the human genome. Nature. 2004;431(7011):931-945.

59. Chen S. Length of a human DNA molecule. 1998. Available from: http://hypertextbook.com/facts/1998/StevenChen.shtml. Accessed September 4, 2012.

60. van Holde K, Zlatanova J, Arents G, Moudrianakis E. Elements of chromatin structure: histones, nucleosomes, and fibres. In: Elgin SCR, editor. Chromtin Structure and Gene Expression. New York: IRL Press; 1995:1-26.

61. Miranda TB, Jones PA. DNA methylation: the nuts and bolts of repression. J Cell Physiol. 2007;213(2):384-390.

62. Bernstein BE, Meissner A, Lander ES. The mammalian epigenome. Cell. 2007;128(4):669-681.

63. Gardiner-Garden M, Frommer M. CpG islands in vertebrate genomes. J Mol Biol. 1987;196(2):261-282.

64. Takai D, Jones PA. Comprehensive analysis of $\mathrm{CpG}$ islands in human chromosomes 21 and 22. Proc Natl Acad Sci U S A. 2002;99(6): 3740-3745.

65. Illingworth RS, Bird AP. CpG islands - 'a rough guide'. FEBS Lett. 2009;583(11):1713-1720.

66. Law JA, Jacobsen SE. Establishing, maintaining and modifying DNA methylation patterns in plants and animals. Nat Rev Genet. 2010;11(3):204-220.

67. Bruniquel D, Schwartz RH. Selective, stable demethylation of the interleukin-2 gene enhances transcription by an active process. Nat Immunol. 2003;4(3):235-240.

68. Oswald J, Engemann S, Lane N, et al. Active demethylation of the paternal genome in the mouse zygote. Curr Biol. 2000;10(8):475-478.

69. Zhang F, Pomerantz JH, Sen G, Palermo AT, Blau HM. Active tissuespecific DNA demethylation conferred by somatic cell nuclei in stable heterokaryons. Proc Natl Acad Sci U S A. 2007;104(11):4395-4400.

70. Martinowich K, Hattori D, Wu H, et al. DNA methylation-related chromatin remodeling in activity-dependent BDNF gene regulation. Science. 2003;302(5646):890-893.

71. Tahiliani M, Koh KP, Shen Y, et al. Conversion of 5-methylcytosine to 5-hydroxymethylcytosine in mammalian DNA by MLL partner TET1. Science. 2009;324(5929):930-935.

72. Ito S, D'Alessio AC, Taranova OV, Hong K, Sowers LC, Zhang Y. Role of Tet proteins in $5 \mathrm{mC}$ to $5 \mathrm{hmC}$ conversion, ES-cell self-renewal and inner cell mass specification. Nature. 2010;466(7310):1129-1133.

73. Wu H, Zhang Y. Mechanisms and functions of Tet protein-mediated 5-methylcytosine oxidation. Genes Dev. 2011;25(23):2436-2452. 
74. Ito S, Shen L, Dai Q, et al. Tet proteins can convert 5-methylcytosine to 5-formylcytosine and 5-carboxylcytosine. Science. 2011;333(6047): $1300-1303$.

75. Bhutani N, Burns DM, Blau HM. DNA demethylation dynamics. Cell. 2011;146(6):866-872.

76. Jeffery L, Nakielny S. Components of the DNA methylation system of chromatin control are RNA-binding proteins. J Biol Chem. 2004; 279(47):49479-49487.

77. Hendrich B, Bird A. Identification and characterization of a family of mammalian methyl-CpG binding proteins. Mol Cell Biol. 1998;18(11): 6538-6547.

78. Zhang Y, Ng HH, Erdjument-Bromage H, Tempst P, Bird A, Reinberg D. Analysis of the NuRD subunits reveals a histone deacetylase core complex and a connection with DNA methylation. Genes Dev. 1999; 13(15):1924-1935.

79. Yildirim $\mathrm{O}$, Li R, Hung JH, et al. Mbd3/NURD complex regulates expression of 5-hydroxymethylcytosine marked genes in embryonic stem cells. Cell. 2011;147(7):1498-1510.

80. Wang GG, Allis CD, Chi P. Chromatin remodeling and cancer, Part I: Covalent histone modifications. Trends Mol Med. 2007;13(9): 363-372.

81. Tan M, Luo H, Lee S, et al. Identification of 67 histone marks and histone lysine crotonylation as a new type of histone modification. Cell. 2011;146(6):1016-1028.

82. Kouzarides T. Chromatin modifications and their function. Cell. 2007;128(4):693-705

83. Shogren-Knaak M, Peterson CL. Switching on chromatin: mechanistic role of histone H4-K16 acetylation. Cell Cycle. 2006;5(13):1361-1365.

84. Shogren-Knaak M, Ishii H, Sun JM, Pazin MJ, Davie JR, Peterson CL. Histone H4-K16 acetylation controls chromatin structure and protein interactions. Science. 2006;311(5762):844-847.

85. Strahl BD, Allis CD. The language of covalent histone modifications. Nature. 2000;403(6765):41-45.

86. Rando OJ. Combinatorial complexity in chromatin structure and function: revisiting the histone code. Curr Opin Genet Dev. 2012;22(2): $148-155$.

87. Zain J, O'Connor OA. Targeting histone deacetylases in the treatment of B- and T-cell malignancies. Invest New Drugs. 2010;28 Suppl 1: S58-S78.

88. Kim HJ, Bae SC. Histone deacetylase inhibitors: molecular mechanisms of action and clinical trials as anti-cancer drugs. Am J Transl Res. 2011; 3(2):166-179.

89. Dietz KC, Casaccia P. HDAC inhibitors and neurodegeneration: at the edge between protection and damage. Pharmacol Res. 2010;62(1): $11-17$.

90. Grabiec AM, Tak PP, Reedquist KA. Function of histone deacetylase inhibitors in inflammation. Crit Rev Immunol. 2011;31(3):233-263.

91. Barski A, Cuddapah S, Cui K, et al. High-resolution profiling of histone methylations in the human genome. Cell. 2007;129(4):823-837.

92. Heintzman ND, Stuart RK, Hon G, et al. Distinct and predictive chromatin signatures of transcriptional promoters and enhancers in the human genome. Nat Genet. 2007;39(3):311-318

93. Schones DE, Cui K, Cuddapah S, et al. Dynamic regulation of nucleosome positioning in the human genome. Cell. 2008;132(5):887-898.

94. Fish JE, Yan MS, Matouk CC, et al. Hypoxic repression of endothelial nitric-oxide synthase transcription is coupled with eviction of promoter histones. J Biol Chem. 2010;285(2):810-826.

95. Flaus A, Owen-Hughes T. Mechanisms for ATP-dependent chromatin remodelling: the means to the end. FEBS J. 2011;278(19):3579-3595.

96. Creyghton MP, Markoulaki S, Levine SS, et al. H2AZ is enriched at polycomb complex target genes in ES cells and is necessary for lineage commitment. Cell. 2008;135(4):649-661.

97. Bai L, Morozov AV. Gene regulation by nucleosome positioning. Trends Genet. 2010;26(11):476-483.

98. Rinn JL, Chang HY. Genome regulation by long noncoding RNAs. Annu Rev Biochem. 2012;81:145-166.
99. Tryndyak VP, Beland FA, Pogribny IP. E-cadherin transcriptional down-regulation by epigenetic and microRNA-200 family alterations is related to mesenchymal and drug-resistant phenotypes in human breast cancer cells. Int J Cancer. 2010;126(11): $2575-2583$.

100. Kim DH, Saetrom P, Snove O Jr, Rossi JJ. MicroRNA-directed transcriptional gene silencing in mammalian cells. Proc Natl Acad Sci US A. 2008;105(42):16230-16235.

101. Rink C, Khanna S. MicroRNA in ischemic stroke etiology and pathology. Physiol Genomics. 2011;43(10):521-528.

102. Ho JJ, Metcalf JL, Yan MS, et al. Functional importance of dicer protein in the adaptive cellular response to hypoxia. $J$ Biol Chem. 2012;287(34):29003-29020.

103. MercerTR, Dinger ME, Mattick JS. Long non-coding RNAs: insights into functions. Nat Rev Genet. 2009;10(3):155-159.

104. Erwin JA, Lee JT. New twists in X-chromosome inactivation. Current Opin Cell Biol. 2008;20(3):349-355.

105. Mikkelsen TS, Ku M, Jaffe DB, et al. Genome-wide maps of chromatin state in pluripotent and lineage-committed cells. Nature. 2007;448(7153):553-560.

106. Guttman M, Amit I, Garber M, et al. Chromatin signature reveals over a thousand highly conserved large non-coding RNAs in mammals. Nature. 2009;458(7235):223-227.

107. Khalil AM, Guttman M, Huarte M, et al. Many human large intergenic noncoding RNAs associate with chromatin-modifying complexes and affect gene expression. Proc Natl Acad Sci U S A. 2009; 106(28):11667-11672

108. Wang KC, Yang YW, Liu B, et al. A long noncoding RNA maintains active chromatin to coordinate homeotic gene expression. Nature. 2011;472(7341):120-124.

109. Rinn JL, Kertesz M, Wang JK, et al. Functional demarcation of active and silent chromatin domains in human HOX loci by noncoding RNAs. Cell. 2007;129(7):1311-1323.

110. Kotake Y, Nakagawa T, Kitagawa K, et al. Long non-coding RNA ANRIL is required for the PRC2 recruitment to and silencing of p15(INK4B) tumor suppressor gene. Oncogene. 2011;30(16): 1956-1962.

111. Manolio TA. Genomewide association studies and assessment of the risk of disease. N Engl J Med. 2010;363(2):166-176.

112. Fraga MF, Ballestar E, Paz MF, et al. Epigenetic differences arise during the lifetime of monozygotic twins. Proc Natl Acad Sci U SA. 2005;102(30):10604-10609.

113. Yang X, Smith SL, Tian XC, Lewin HA, Renard JP, Wakayama T. Nuclear reprogramming of cloned embryos and its implications for therapeutic cloning. Nat Genet. 2007;39(3):295-302.

114. Morgan HD, Sutherland HG, Martin DI, Whitelaw E. Epigenetic inheritance at the agouti locus in the mouse. Nat Genet. 1999;23(3): 314-318.

115. Chan TL, Yuen ST, Kong CK, et al. Heritable germline epimutation of MSH2 in a family with hereditary nonpolyposis colorectal cancer. Nat Genet. 2006;38(10):1178-1183.

116. Hitchins MP, Wong JJ, Suthers G, et al. Inheritance of a cancerassociated MLH1 germ-line epimutation. $N$ Engl J Med. 2007;356(7): 697-705.

117. Suter CM, Martin DI, Ward RL. Germline epimutation of MLH1 in individuals with multiple cancers. Nat Genet. 2004;36(5): 497-501.

118. Freson K, Izzi B, Van Geet C. From genetics to epigenetics in platelet research. Thromb Res. 2012;129(3):325-329.

119. Goodeve AC, Perry DJ, Cumming T, et al. Genetics of haemostasis. Haemophilia. 2012;18 Suppl 4:73-80.

120. Guttman M, Rinn JL. Modular regulatory principles of large noncoding RNAs. Nature. 2012;482(7385):339-346.

121. Wilcox JN, Subramanian RR, Sundell CL, et al. Expression of multiple isoforms of nitric oxide synthase in normal and atherosclerotic vessels. Arterioscler Thromb Vasc Biol. 1997;17(11):2479-2488. 
122. Oemar BS, Tschudi MR, Godoy N, Brovkovich V, Malinski T, Luscher TF. Reduced endothelial nitric oxide synthase expression and production in human atherosclerosis. Circulation. 1998;97(25): 2494-2498.

123. Brown MS, Goldstein JL. A receptor-mediated pathway for cholesterol homeostasis. Science. 1986;232(4746):34-47.

124. Malek AM, Alper SL, Izumo S. Hemodynamic shear stress and its role in atherosclerosis. JAMA. 1999;282(21):2035-2042.

125. Won D, Zhu SN, Chen M, et al. Relative reduction of endothelial nitricoxide synthase expression and transcription in atherosclerosis-prone regions of the mouse aorta and in an in vitro model of disturbed flow. Am J Pathol. 2007;171(5):1691-1704.

126. Hajra L, Evans AI, Chen M, Hyduk SJ, Collins T, Cybulsky MI. The NF-kappa B signal transduction pathway in aortic endothelial cells is primed for activation in regions predisposed to atherosclerotic lesion formation. Proc Natl Acad Sci U S A. 2000;97(16): 9052-9057.

127. Cui X, Chopp M, Zacharek A, Zhang C, Roberts C, Chen J. Role of endothelial nitric oxide synthetase in arteriogenesis after stroke in mice. Neuroscience. 2009;159(2):744-750.

128. Lo EH, Hara H, Rogowska J, et al. Temporal correlation mapping analysis of the hemodynamic penumbra in mutant mice deficient in endothelial nitric oxide synthase gene expression. Stroke. 1996;27(8): 1381-1385

129. Huang Z, Huang PL, Panahian N, Dalkara T, Fishman MC, Moskowitz MA. Effects of cerebral ischemia in mice deficient in neuronal nitric oxide synthase. Science. 1994;265(5180):1883-1885.

130. Tsui AK, Marsden PA, Mazer CD, et al. Priming of hypoxia-inducible factor by neuronal nitric oxide synthase is essential for adaptive responses to severe anemia. Proc Natl Acad Sci U SA. 2011;108(42): 17544-17549.

131. Pruss H, Prass K, Ghaeni L, et al. Inducible nitric oxide synthase does not mediate brain damage after transient focal cerebral ischemia in mice. J Cereb Blood Flow Metab. 2008;28(3):526-539.

132. Fajas L, Fruchart JC, Auwerx J. Transcriptional control of adipogenesis. Curr Opin Cell Biol. 1998;10(2):165-173.

133. McKinsey TA, Zhang CL, Olson EN. Signaling chromatin to make muscle. Curr Opin Cell Biol. 2002;14(6):763-772.

134. Marsden PA, Schappert KT, Chen HS, et al. Molecular cloning and characterization of human endothelial nitric oxide synthase. FEBS Lett. 1992;307(3):287-293.

135. Marsden PA, Heng HH, Scherer SW, et al. Structure and chromosomal localization of the human constitutive endothelial nitric oxide synthase gene. J Biol Chem. 1993;268(23):17478-17488.

136. Tai SC, Robb GB, Marsden PA. Endothelial nitric oxide synthase: a new paradigm for gene regulation in the injured blood vessel. Arterioscler Thromb Vasc Biol. 2004;24(3):405-412.

137. Karantzoulis-Fegaras F, Antoniou H, Lai SL, et al. Characterization of the human endothelial nitric-oxide synthase promoter. J Biol Chem 1999;274(5):3076-3093.

138. Chan Y, Fish JE, D'Abreo C, et al. The cell-specific expression of endothelial nitric-oxide synthase: a role for DNA methylation. J Biol Chem. 2004;279(33):35087-35100.

139. Guillot PV, Liu L, Kuivenhoven JA, Guan J, Rosenberg RD, Aird WC. Targeting of human eNOS promoter to the Hprt locus of mice leads to tissue-restricted transgene expression. Physiol Genomics. 2000;2(2):77-83.

140. Teichert AM, Miller TL, Tai SC, et al. In vivo expression profile of an endothelial nitric oxide synthase promoter-reporter transgene. $\mathrm{Am}$ J Physiol Heart Circ Physiol. 2000;278(4):H1352-H1361.

141. Fish JE, Matouk CC, Rachlis A, et al. The expression of endothelial nitric-oxide synthase is controlled by a cell-specific histone code. J Biol Chem. 2005;280(26):24824-24838.

142. Fish JE, Matouk CC, Yeboah E, et al. Hypoxia-inducible expression of a natural cis-antisense transcript inhibits endothelial nitric-oxide synthase. J Biol Chem. 2007;282(21):15652-15666.
143. Robb GB, Carson AR, Tai SC, et al. Post-transcriptional regulation of endothelial nitric-oxide synthase by an overlapping antisense mRNA transcript. J Biol Chem. 2004;279(36):37982-37996.

144. Pasmant E, Laurendeau I, Heron D, Vidaud M, Vidaud D, Bieche I. Characterization of a germ-line deletion, including the entire INK4/ ARF locus, in a melanoma-neural system tumor family: identification of ANRIL, an antisense noncoding RNA whose expression coclusters with ARF. Cancer Res. 2007;67(8):3963-3969.

145. Helgadottir A, Thorleifsson G, Manolescu A, et al. A common variant on chromosome 9p21 affects the risk of myocardial infarction. Science. 2007;316(5830):1491-1493.

146. McPherson R, Pertsemlidis A, Kavaslar N, et al. A common allele on chromosome 9 associated with coronary heart disease. Science. 2007;316(5830):1488-1491.

147. Samani NJ, Erdmann J, Hall AS, et al. Genomewide association analysis of coronary artery disease. N Engl J Med. 2007;357(5): 443-453.

148. Wellcome Trust Case Control Consortium. Genome-wide association study of 14,000 cases of seven common diseases and 3,000 shared controls. Nature. 2007;447(7145):661-678.

149. Bilguvar K, Yasuno K, Niemela M, et al. Susceptibility loci for intracranial aneurysm in European and Japanese populations. Nat Genet. 2008;40(12):1472-1477.

150. Burd CE, Jeck WR, Liu Y, Sanoff HK, Wang Z, Sharpless NE. Expression of linear and novel circular forms of an INK4/ARFassociated non-coding RNA correlates with atherosclerosis risk. PLoS Genet. 2010;6(12):e1001233.

151. Congrains A, Kamide K, Katsuya T, et al. CVD-associated non-coding RNA, ANRIL, modulates expression of atherogenic pathways in VSMC. Biochem Biophys Res Commun. 2012;419(4):612-616.

152. Folkersen L, Kyriakou T, Goel A, et al. Relationship between CAD risk genotype in the chromosome 9p21 locus and gene expression. Identification of eight new ANRIL splice variants. PloS One. 2009;4(11):e7677.

153. Langley B, Brochier C, Rivieccio MA. Targeting histone deacetylases as a multifaceted approach to treat the diverse outcomes of stroke. Stroke. 2009;40(8):2899-2905.

154. Qureshi I, Mehler M. Chromatin-modifying agents for epigenetic reprogramming and endogenous neural stem cell-mediated repair in stroke. Transl Stroke Res. 2011;2(1):7-16.

155. Gil J, Peters G. Regulation of the INK4b-ARF-INK4a tumour suppressor locus: all for one or one for all. Nat Rev Mol Cell Biol. 2006;7(9):667-677.

156. Endres M, Meisel A, Biniszkiewicz D, et al. DNA methyltransferase contributes to delayed ischemic brain injury. J Neurosc. 2000;20(9): 3175-3181.

157. Endres M, Fan G, Meisel A, Dirnagl U, Jaenisch R. Effects of cerebral ischemia in mice lacking DNA methyltransferase 1 in post-mitotic neurons. Neuroreport. 2001;12(17):3763-3766.

158. Faraco G, Pancani T, Formentini L, et al. Pharmacological inhibition of histone deacetylases by suberoylanilide hydroxamic acid specifically alters gene expression and reduces ischemic injury in the mouse brain. Mol Pharmacol. 2006;70(6):1876-1884.

159. Ren M, Leng Y, Jeong M, Leeds PR, Chuang DM. Valproic acid reduces brain damage induced by transient focal cerebral ischemia in rats: potential roles of histone deacetylase inhibition and heat shock protein induction. J Neurochem. 2004;89(6): 1358-1367.

160. Yildirim F, Gertz K, Kronenberg G, et al. Inhibition of histone deacetylation protects wildtype but not gelsolin-deficient mice from ischemic brain injury. Exp Neurol. 2008;210(2):531-542.

161. Langley B, D’Annibale MA, Suh K, et al. Pulse inhibition of histone deacetylases induces complete resistance to oxidative death in cortical neurons without toxicity and reveals a role for cytoplasmic p21(waf1/cip1) in cell cycle-independent neuroprotection. JNeurosci. 2008;28(1):163-176. 
162. Jeyaseelan K, Lim KY, Armugam A. MicroRNA expression in the blood and brain of rats subjected to transient focal ischemia by middle cerebral artery occlusion. Stroke. 2008;39(3):959-966.

163. Dharap A, Bowen K, Place R, Li LC, Vemuganti R. Transient focal ischemia induces extensive temporal changes in rat cerebral microRNAome. J Cereb Blood Flow Metab. 2009;29(4):675-687.

164. Qureshi IA, Mehler MF. Emerging role of epigenetics in stroke: part 1: DNA methylation and chromatin modifications. Arch Neurol. 2010; 67(11):1316-1322.
165. Qureshi IA, Mehler MF. The emerging role of epigenetics in stroke: II. RNA regulatory circuitry. Arch Neurol. 2010;67(12):1435-1441.

166. Qureshi IA, Mehler MF. The emerging role of epigenetics in stroke: III. Neural stem cell biology and regenerative medicine. Arch Neurol. 2011;68(3):294-302.

167. Zaina S, Dossing KB, Lindholm MW, Lund G. Chromatin modification by lipids and lipoprotein components: an initiating event in atherogenesis? Curr Opin Lipidol. 2005;16(5):549-553.

\section{Publish your work in this journal}

Advances in Genomics and Genetics is an international, peer reviewed, open access journal that focuses on new developments in characterizing the human and animal genome and specific gene expressions in health and disease. Particular emphasis will be given to those studies that elucidate genes, biomarkers and targets in the development of new or improved therapeutic interventions. The journal is characterized by the rapid reporting of reviews, original research, methodologies, technologies and analytics in this subject area. The manuscript management system is completely online and includes a very quick and fair peer-review system. Visit http://www.dovepress.com/ testimonials.php to read real quotes from published authors.

Submit your manuscript here: http://www.dovepress.com/advances-in-genomics-and-gene-expression-journal 